\title{
LOS ALAMOS NATIONAL LABORATORY SUMMARY PLAN TO FABRICATE MIXED OXIDE LEAD ASSEMBLIES FOR THE FISSILE MATERIAL DISPOSITION PROGRAM
}

J. J. Buksa, S. L. Eaton, H. Trellue, K. Chidester, M. Bowidowicz, R. A. Morley, and M. J. Barr

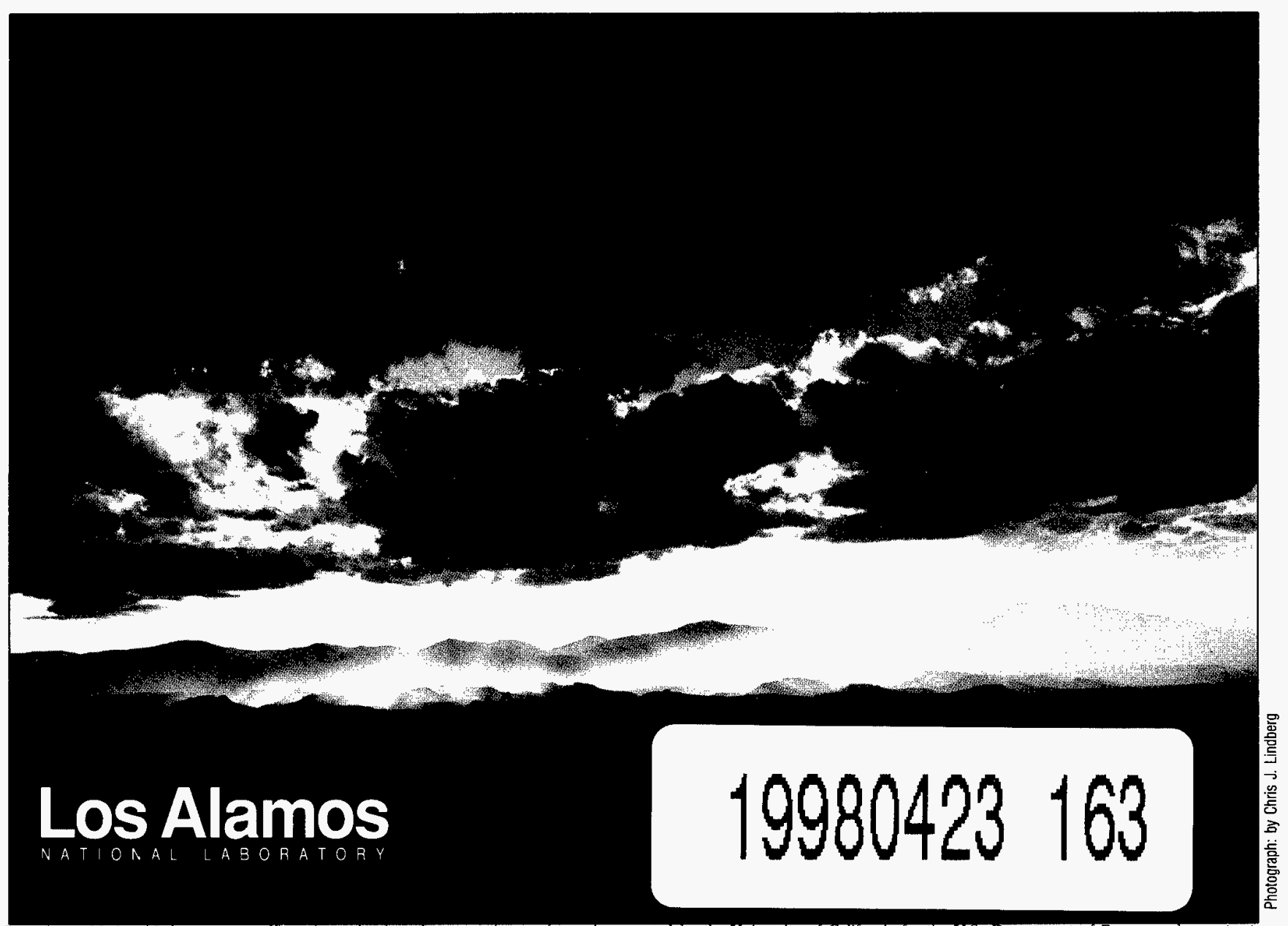




\section{DISCLAIMER}

This report was prepared as an account of work sponsored by an agency of the United States Government. Neither the United States Government nor any agency thereof, nor any of their empioyees, makes any warranty, express or implied, or assumes any legal liability or responsibility for the accuracy, completeness, or usefulness of any information, apparatus, product, or process disclosed, or represents that its use would not infringe privately owned rights. Reference herein to any specific commercial product, process, or service by trade name, trademark, manufacturer, or otherwise does not necessarily constitute or imply its endorsement, recommendation, or favoring by the United States Government or any agency thereof. The views and opinions of authors expressed herein do not necessarily state or reflect those of the United States Government or any agency thereof. 


\section{Los Alamos National Laboratory Summary Plan to Fabricate Mixed Oxide Lead Assemblies for the Fissile Material Disposition Program}

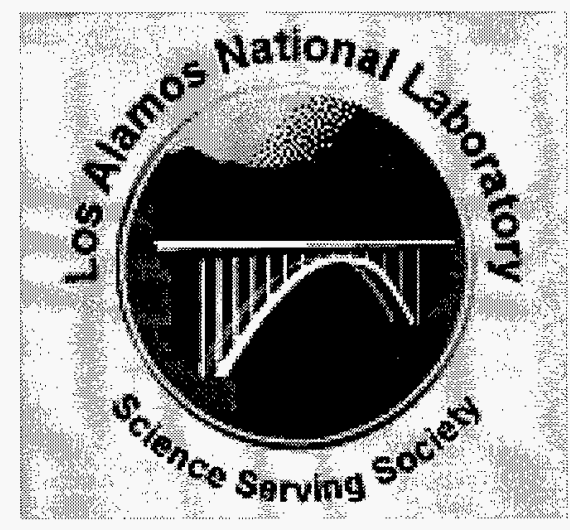

December 22, 1997

Nuclear Materials \& Stockpile Management Programs Technology \& Safety Assessment Division Nuclear Materials Technology Division Earth \& Environment Science Division Facilities, Safeguards, and Securities Division Chemical Science \& Technology Division Materials Science Technology Division 


\section{EXECUTIVE SUMMARY}

This report summarizes an approach for using existing Los Alamos National Laboratory (Laboratory) mixed oxide (MOX) fuel-fabrication and plutonium processing capabilities to expedite and assure progress in the MOX/Reactor Plutonium Disposition Program. Lead Assembly MOX fabrication is required to provide prototypic fuel for testing in support of fuel qualification and licensing requirements. It is also required to provide a bridge for the full utilization of the European fabrication experience. In part, this bridge helps establish, for the first time since the early 1980s, a United States (US) experience base for meeting the safety, licensing, safeguards, security, and materials control and accountability requirements of the Department of Energy and Nuclear Regulatory Commission. In addition, a link is needed between the current research and development program and the production of disposition mission fuel. This link would also help provide a knowledge base for US regulators. Early MOX fabrication and irradiation testing in commercial nuclear reactors would provide a positive demonstration to Russia (and to potential vendors, designers, fabricators, and utilities) that the US has serious intent to proceed with plutonium disposition.

The Laboratory baseline plan for fabricating MOX fuel lead assemblies relies on the use of three existing facilities: TA-55/PF-4 for powder processing, pellet fabrication, rod fabrication, and material characterization; TA-50/37 Radioactive Materials Research, Operations, and Demonstration (RAMROD) for rod nondestructive examination (NDE) and bundle assembly; and the Chemistry and Metallurgy Research facility (CMR) for analytical chemistry. Powder processing and pellet fabrication will take place in the currently operating fuel-fabrication laboratory in PF-4; rooms 128, 126, and 125 will be upgraded with several new pieces of processing equipment including a prototypic ceramic furnace (pusher continuous or pot-batch type). Rod fabrication will be located in room 201. Once these rods have been verified as leak tight and contamination free, they will be transported in batch-size lots to the RAMROD facility for nuclear and nonnuclear NDE. They will then be transported back to PF-4 for storage in a basement-secure cage. If only rods are required for irradiation, they can be shipped directoy from $\mathrm{PF}-4$. If bundles of full MOX fuel rods or mixed $\mathrm{MOX}$ and $\mathrm{UO}_{2}$ fuel rods are required for irradiation, shortly before bundle transportation off site, the appropriate rods will be transported back to the RAMROD facility where they will be assembled into a bundle, which will then be examined, loaded into the cask insert, packaged in the transportation cask, and immediately shipped off site or shipped back to PF-4 for longer-term storage. Several alternative facilities for the bundling operation were considered (such as the CMR building) and are available as a backup. 


\section{TABLE OF CONTENTS}

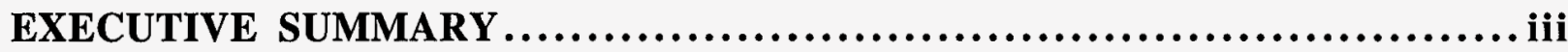

TABLE OF CONTENTS................................................ iv

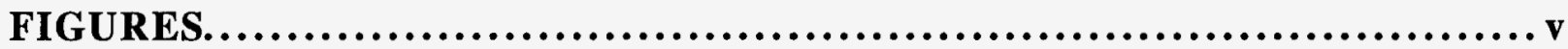

1.0. INTRODUCTION..................................................

2.0. PROPOSED OPTION.............................................2

3.0. FACILITY DESCRIPTIONS...................................... 3

3.1. PLUTONIUM FACILITY (PF-4) .......................................................

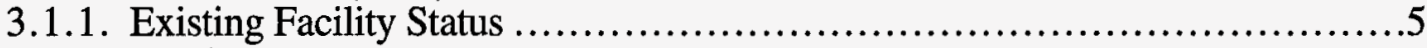

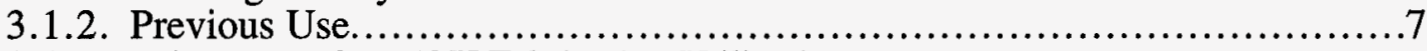

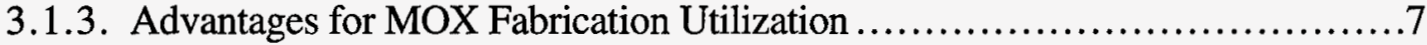

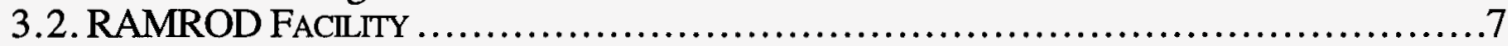

3.3. CHEMISTRY AND METALLURGY RESEARCH FACLITY .............................. 10

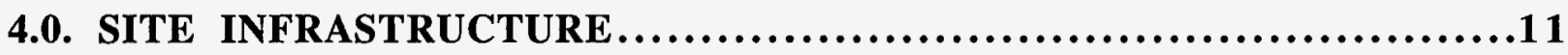

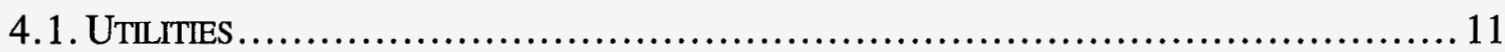

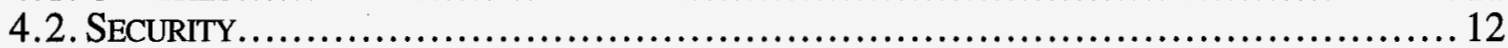

4.2.1. Protective Force and Physical Security ..................................... 13

4.2.2. Materials Control and Accountability ................................. 13

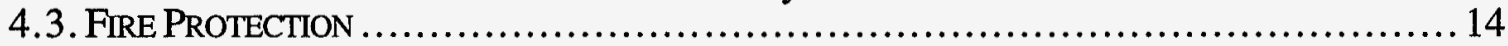

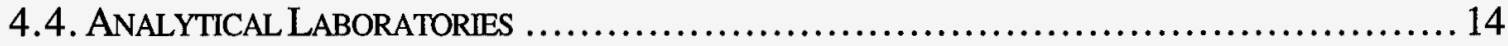

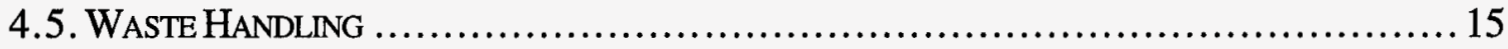

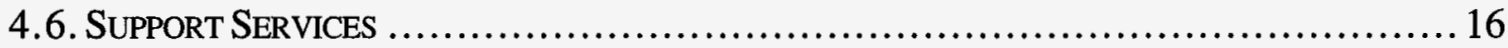

4.7. REGULATION AND PERMITTING................................................. 17

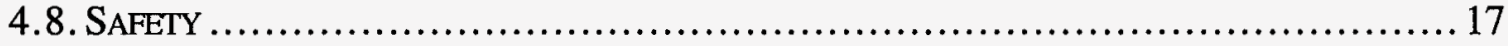

5.0. PROCESS INTERFACE DESCRIPTIONS .............................18

5.1. Feed Material Receiving ....................................................... 18

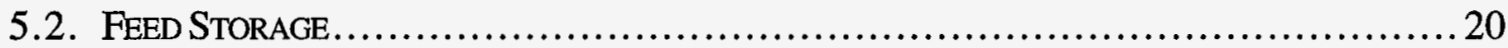

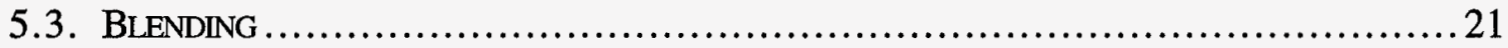

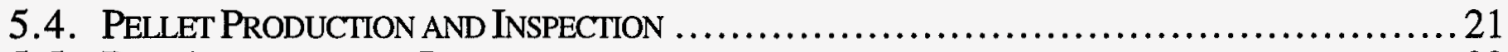

5.5. ROD ASSEMBLY AND INSPECTION................................................... 22

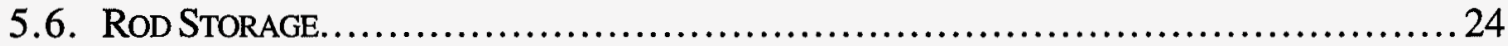

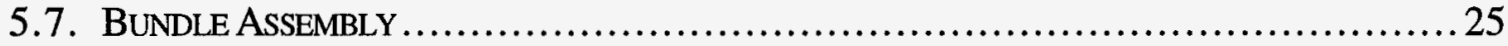

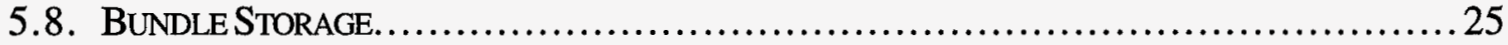

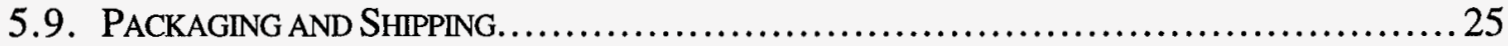

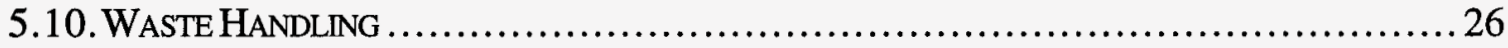

6.0. PROPOSED FACILITY MODIFICATIONS $\ldots \ldots \ldots \ldots \ldots \ldots \ldots \ldots \ldots \ldots \ldots . \ldots \ldots$

6.1. INSTALLATION OF MOX FUEL-FABRICATION EQUIPMENT ............................... 26

6.2. ACHIEVING DOE ORDER COMPLIANCE .......................................... 27

7.0. RESOURCES AND MANPOWER...............................27

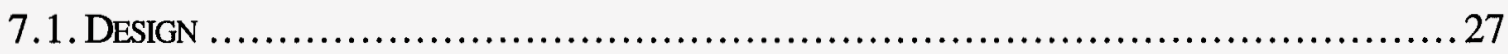

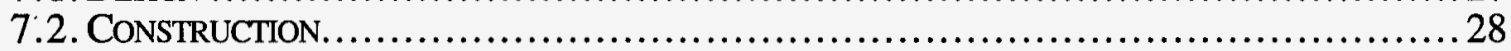




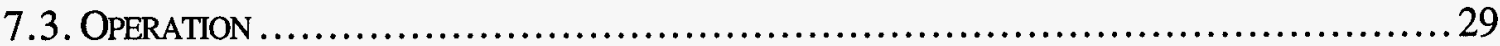

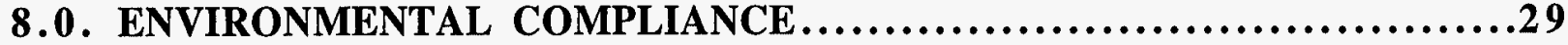

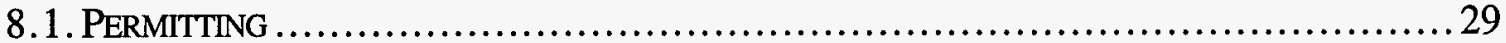

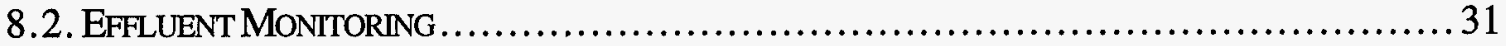

8.2.1. Air Sampling/Monitoring Programs................................... 31

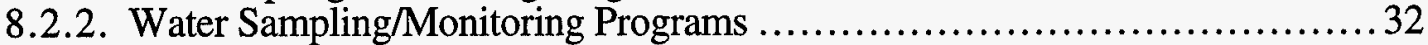

8.2.3. Sediments, Soil, and Foodstuffs ........................................ 33

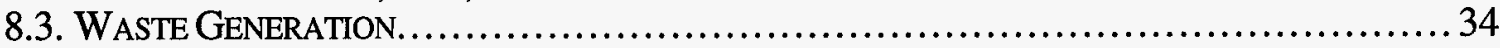

8.3.1. Resource Conservation and Recovery Act ................................34

8.3.2. Comprehensive Environmental Response, Compensation, and Liability Act. . 34

9.0. CONCLUSIONS...............................................34

10.0.REFERENCES..................................................34

\section{FIGURES}

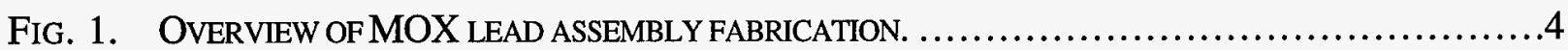

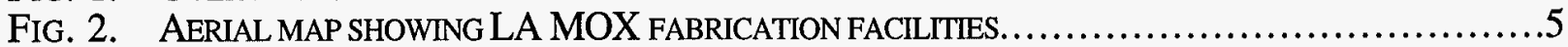

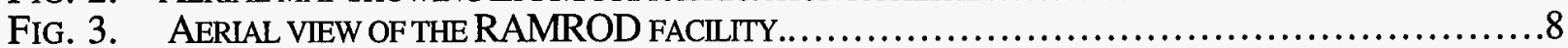

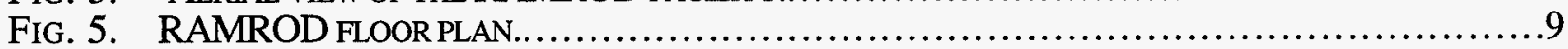

FIG. 6. AERIAL VIEW OF CMR FACLITY........................................................... 10

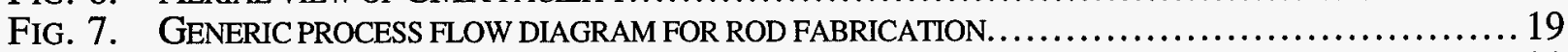

FIG. 8. GENERIC PROCESS FLOW DIAGRAM FOR ROD NDE AND BUNDLE ASSEMBLY ..................2 20

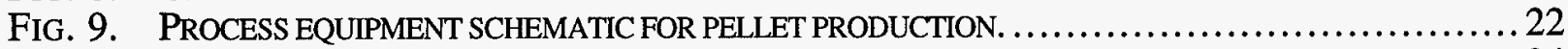

FIG. 10. RAMROD ROOM 114 FLOOR PLAN WITH POTENTIAL NDE AND BUNDLE ASSEMBLY STATIONS. 24 


\title{
LOS ALAMOS NATIONAL LABORATORY SUMMARY PLAN TO FABRICATE MIXED OXIDE LEAD ASSEMBLIES FOR THE FISSILE MATERIAL DISPOSITION PROGRAM
}

\author{
J. J. Buksa, S. L. Eaton, H. R. Trellue, K. Chidester, M. Bowidowicz, \\ R. A. Morley, and M. Barr
}

\subsection{INTRODUCTION}

In January 1997, the Department of Energy (DOE) issued a Record of Decision (ROD) with regard to storage and disposition of surplus weapons-usable fissile materials. As part of the ROD, DOE stated that the

"..strategy for disposition of surplus plutonium is to pursue an approach that allows immobilization of surplus plutonium in glass or ceramic material for disposal in a geologic repository, pursuant to the Nuclear Waste Policy Act, and burning of some of the surplus plutonium as mixed oxide (MOX) fuel in existing, domestic, commercial reactors, with subsequent disposal of the spent fuel in a geologic repository, pursuant to the Nuclear Waste Policy Act."*

The ROD went on to state that

"..the principal uncertainty with respect to using excess weapons plutonium as MOX in U.S. LWRs relates to the potential difficulty of gaining political and regulatory approvals for the various operations required."

Early insertion of MOX fuel containing weapons-derived plutonium in commercial power reactors would enhance the resolution of most of the uncertainties in this regard before the operation of a full-scale MOX fuel-fabrication facility. Now the only facilities currently producing MOX fuel suitable for insertion in commercial power reactors are in Europe. Use of European MOX fabrication capacities is unlikely because of daunting political obstacles to the shipment of US weapons plutonium to Europe. Therefore, near-term insertion of MOX fuel into commercial reactors will require fabrication of the fuel in a domestic facility.

Currently, the Los Alamos National Laboratory (Laboratory) has the technical lead for MOX fuel fabrication for the Fissile Material Disposition (FMD) Program, with a fiscal year 1998 (FY98) budget of over $\$ 10 \mathrm{M}$. Half of this budget is spent performing research and development (R\&D) in the areas of feed qualification and supply, fuel-fabrication process development, analytical methods development, and $\mathrm{PuO}_{2}$ feed conditioning. As such, the Laboratory has the best understanding of the issues related to the fabrication of MOX fuel using surplus weapon plutonium. The majority of the R\&D work is carried out in the Laboratory's TA-55 plutonium facility, which is the only operating facility capable of producing MOX fuel in the US. TA-55 is a modern, safeguards Category I facility that meets current safety and environmental requirements as well as safeguards and security criteria. The facility also meets all current federal and state permit and regulatory requirements for plutonium operations. The facility is currently preparing for a possible transition to Nuclear Regulatory Commission (NRC) safety oversight by FY01. The fuel-fabrication process lines in TA-55 have been used since 1979 to produce high-quality fuel for irradiation testing and

* "Record of Decision for the Storage and Disposition of Weapons-Usable Fissile Materials Final Programmatic Environmental Impact Statement," Department of Energy, Washington, D.C., 1997. 
examination.* The product meets rigorous specification and quality assurance standards. Existing personnel are well trained, and the facility safety record is excellent. In short, the TA-55 facility and staff are well positioned to meet near-term schedules at minimum cost to support the MOX lead assembly fuel-fabrication mission. This report summarizes an approach to fabricating lead assembly MOX fuel using the existing MOX fuel-fabrication infrastructure at the Laboratory.

\subsection{PROPOSED OPTION}

Inherent to the lead assembly (LA) MOX fuel-fabrication plan presented here are a number of important assumptions that have been made based on the accumulated experiences to date of fabricating MOX fuel for the Materials Disposition (MD) Program. First, any approach must build on the European MOX fuel-fabrication experience base. Second, because the primary purpose of LA MOX fuel is to support fuel qualification and licensing, it needs to be fabricated using feed materials and processes that are as prototypic as possible. The approach must minimize the cost and schedule regardless of whether funds flow through the winning vendor or come directly through the DOE. The Laboratory approach attains this goal by using its extensive MOX fuelfabrication infrastructure, including facilities with existing authorization bases and demonstrated safe operations, existing plutonium processing and fuel-fabrication equipment, a large cadre of trained and experienced plutonium operating personnel, a validated analytical chemistry and material characterization capability, a complete waste-management system, and the necessary material control and accountability systems to process large quantities of special nuclear material (SNM). Further cost and schedule savings are obtained through the integration of fuel-fabrication and $\mathrm{PuO}_{2}$ production, which may also occur at the Laboratory [in the Advanced Recovery and Integrated Extraction System (ARIES)]. The Laboratory has current National Environmental Policy Agency (NEPA) coverage to continue its benchtop R\&D activities and will have coverage to fabricate full MOX fuel assemblies once its pending Sitewide Environmental Impact Statement is released and a ROD is issued (expected in late FY98). And finally, the Laboratory approach uses existing facilities that have enduring missions so that no facility decontamination/decommissioning will be required at the end of the mission.

In assessing potential facilities and processing schemes, it became evident that the use of the TA-55 PF-4 facility with its authorization to handle large quantities of plutonium would best serve the needs of the FMD Program.** A number of reasons led to this conclusion:

- The worldwide experience base with fabricating qualified light water reactor MOX fuel is in "CAT I"-like facilities that have no limits on $\mathrm{PuO}_{2}$ in-process quantities. Although the use of alternative schemes, such as modifying processes/equipment to accommodate limits in the total inventory of $\mathrm{PuO}_{2}$, is technically possible, it would fall outside of this fabrication experience base.

- The production of $\mathrm{PuO}_{2}$ and its subsequent packaging for storage and disposition mission use would occur in cans containing $\sim 5.0 \mathrm{~kg} \mathrm{PuO}$ in accordance with the DOE

1979-1983: 50-100 kg/yr of UC-PuC fuel for FBR development program.

1981-1988: $\mathrm{UO}_{2}-\mathrm{PuO}_{2}$ fuel for FFTF fast reactor

(16 kg HM, 25\% Pu, 33\% ${ }^{235} \mathrm{U} ; 12 \mathrm{~kg} \mathrm{DUO}{ }_{2}$ insulator pellets).

1984-1990: $150 \mathrm{~kg}$ UN fuel for SP-100 Program [Collaborative effort led by industry [General Electric (GE)] and funded directly by the DOE. The customer for the fuel was GE, who supplied fuel specifications, quality assurance requirements, etc. Test fuel was also fabricated for out-of-pile and in-pile testing. This fuel development and production project spanned 8 years, employed 30 technicians/technical staff members, and produced $\sim 49,000$ qualified fuel pellets.)

** A non-CAT I approach was initially considered that used the CMR facility (CAT III) for all processing. 
packaging standard. ${ }^{*}$ Accommodating smaller quantities $(600 \mathrm{~g} / \mathrm{can}$ ) would entail substantial repackaging costs, would be nonprototypic, and would increase analytical costs, waste costs, and materials control and accountability (MC\&A) concerns and costs.

- The use of a CAT-I facility allows for prototypic first-unit operations such as first stage blending, second-stage blending (or prepress conditioning), pressing, and sintering. This minimizes batch variability and analytical chemistry costs and minimizes material handling, control, and accountability concerns/costs.

- The use of a CAT-I facility enables sufficient and flexible in-process storage capacity. This crucial consideration allows process variations (upsets) to be addressed throughout the entire process.

The Laboratory approach to fabricating MOX fuel lead assemblies is depicted in Fig. 1. Three major facilities are used in this process: TA-55/PF-4; the Radioactive Materials Research, Operations, and Demonstration (RAMROD) facility; and the Chemistry and Metallurgical Research (CMR) facility. The location of each of these facilities is shown in Fig. 2.

The Laboratory approach begins with the receipt of $\mathrm{PuO}_{2}$ at TA-55. It is probable that a majority of the feed material required for this mission will already be in the TA-55/PF-4 vault as $\mathrm{PuO}_{2}$ produced from ARIES demonstration runs. The $\mathrm{UO}_{2}$ and rod/bundle hardware will arrive at TA$55 / \mathrm{PF}-4$ and be stored in the basement in a secure cage dedicated to this mission. Qualification, demonstration, and production campaigns for pellets will be carried out in the fuel-fabrication development lab, primarily rooms 125 and 126 . Completed pellets will be moved to room 201 where they will be incorporated into rods. Once loaded and sealed, each rod will be leak tested and checked for contamination. Finished rods will then be sent to the RAMROD facility for the remaining rod nondestructive examinations (NDE), and sent back to PF-4 for storage in secure fixtures in the basement cage. If only rods are required at the reactor site, they can be shipped directly from PF-4. If bundles are requested at the host reactor site, sufficient time will be allowed for the necessary rods to be moved back to RAMROD where they will be assembled into bundles, inspected, packaged, and shipped off site. In the event that longer storage times are needed, the finished bundles will be moved back to the basement cage in PF-4. Although the baseline approach is to use RAMROD for rod NDE and bundle assembly, a number of other buildings (CMR Wing-9 in particular) are also attractive and available for these activities.

\subsection{FACILITY DESCRIPTIONS}

\subsection{Plutonium Facility (PF-4)}

The Los Alamos National Laboratory Plutonium Facility, Building 4 (PF-4) at Technical Area 55 (TA-55) was approved by the DOE for plutonium operations in April 1978. TA-55 is located at the Los Alamos National Laboratory in Los Alamos, New Mexico, about one mile east-southeast of the main Laboratory buildings on Pajarito Road. It comprises PF-4, offices, and other support buildings within a security fence. Facilities at TA-55 other than PF-4 will be described to the extent that they interface with PF-4. Nuclear operations are only conducted in PF-4. An aerial view of TA-55 is shown in Fig. 3.

* "Criteria for Preparing and Packaging Plutonium Metals and Oxides for Long-Term Storage," DOE-STD-301396, September 1996. 


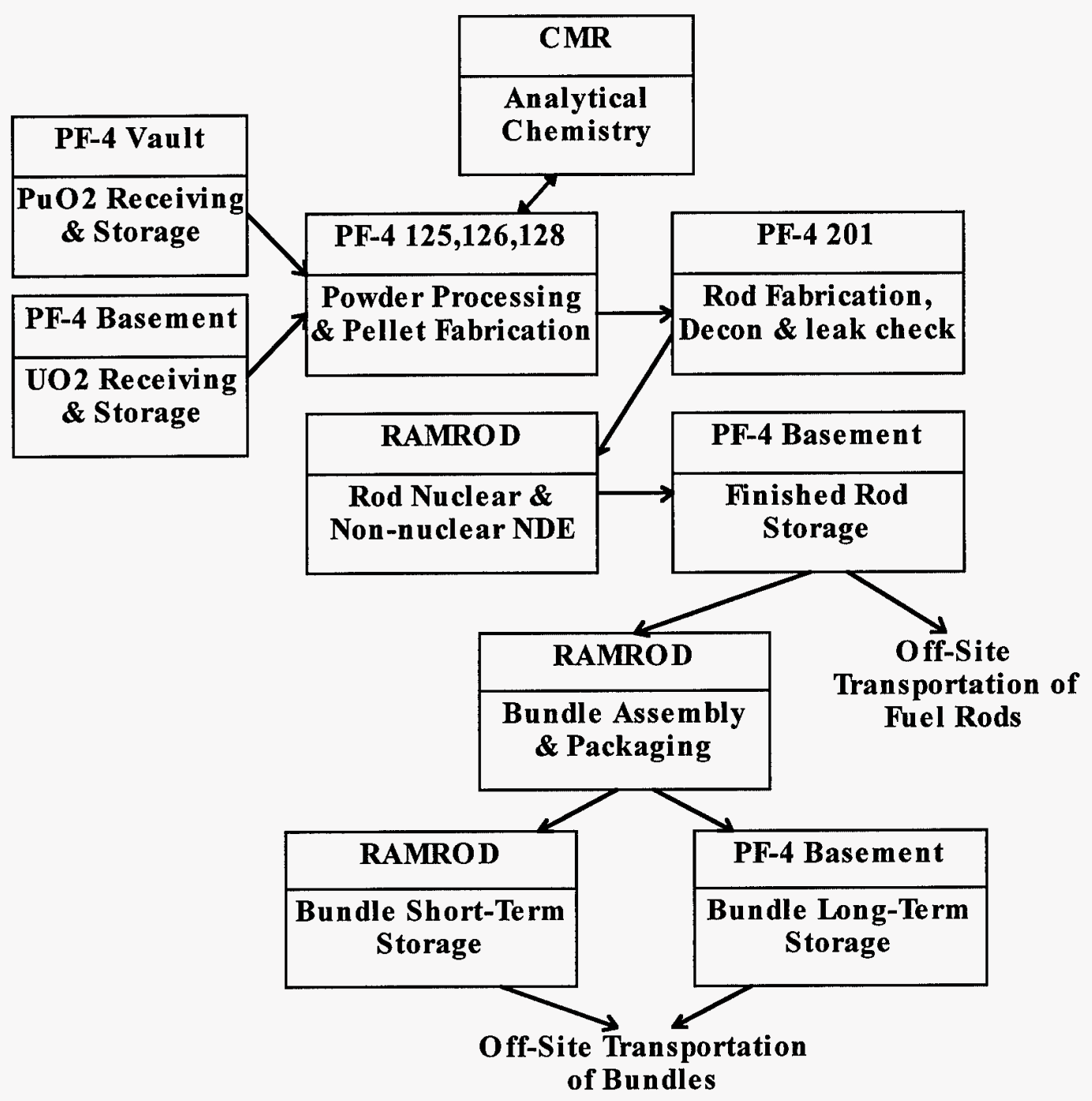

Fig. 1. Overview of MOX lead assembly fabrication.

PF-4 was designed and constructed by Fluor Corporation in the late 1970s. PF-4 is a two-story, reinforced concrete structure that was designed and constructed to remain functional following a design basis earthquake with a peak ground acceleration of $0.33 \mathrm{~g}$, to withstand a wind velocity of 93 miles per hour, and to meet design basis fire safety qualifications. Buildings and structures that are nearby and provide services for PF-4 include the TA-55 Operations Center, support, utility, generator, and administrative buildings, guard stations, and firewater pump houses. Many of the processes and associated equipment in PF-4 were designed by the Laboratory and were moved from a previous site when PF-4 was completed.

The layout of PF-4 comprises two equal halves that are separated by a concrete wall and fire doors. A central corridor running through each half provides access to the laboratory and processing areas on both sides of the corridor. Each half contains its own ventilation system and electrical substation. The basement contains ventilation equipment, electrical equipment, a vault for storage of SNM, and space for some support functions. The ventilation system of PF-4 provides airflow from areas of low probability for radioactive material contamination to areas of higher probability of contamination (i.e., from corridors through laboratories to glove boxes). The airflow passes 


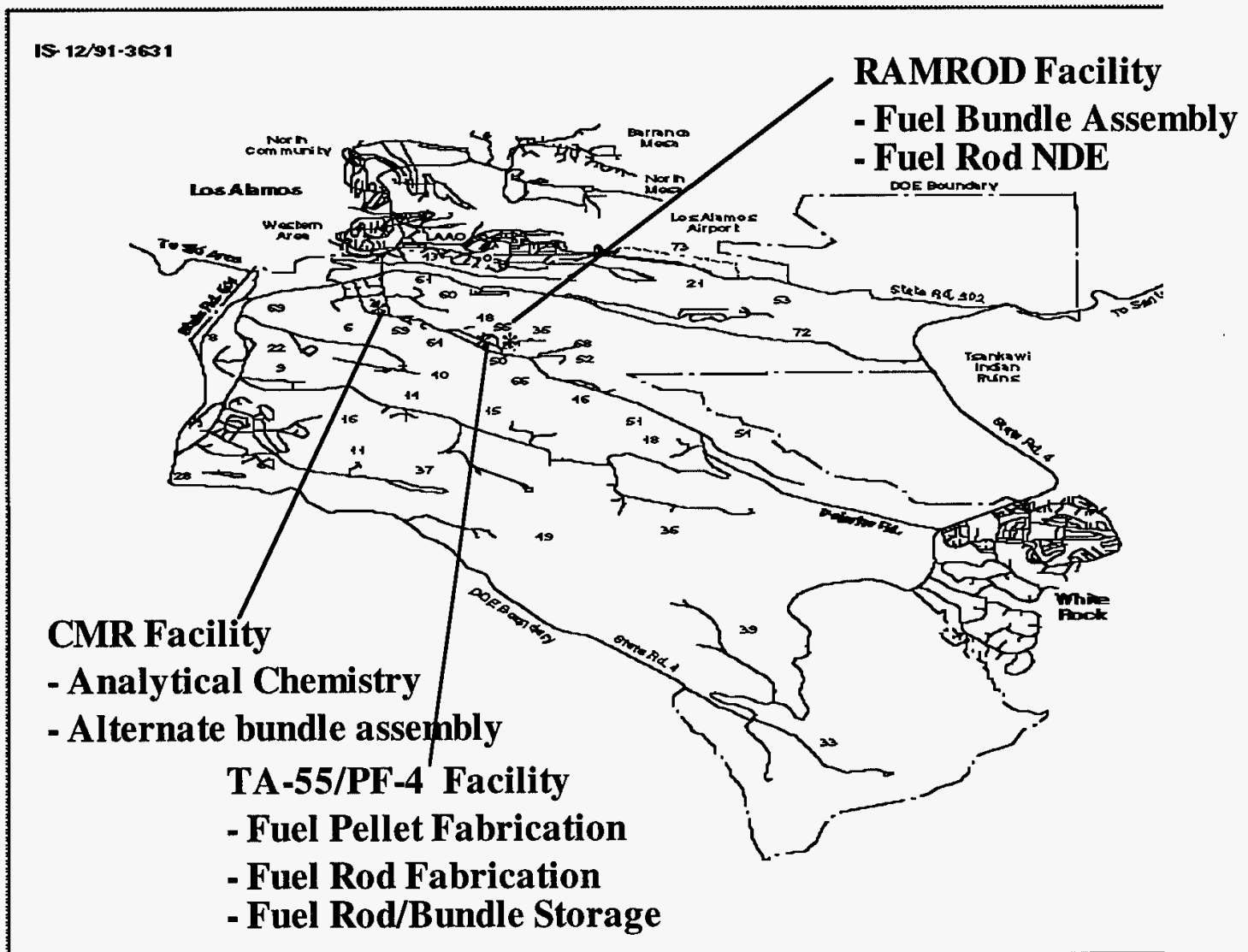

Fig. 2. Aerial map showing LA MOX fabrication facilities.

through multiple banks of high-efficiency particulate air (HEPA) filtration before being released to the environment.

Significant external interfaces for PF-4 include the electrical supply system, the firewater and potable water supply systems, and the sanitary and process waste systems. Support services, which are provided on site, include medical, emergency response, training, radiation protection, and safety. These services are provided on a continuing basis.

Safe operations at TA-55 are based on multiple barriers to the release of hazardous material, welltrained personnel operating in accordance with approved safe operating procedures, and support from management and other Laboratory organizations. Concentration on the reduction of risks to the public, facility workers, and the environment is emphasized in daily operations and is described in detail within the final safety analysis report (FSAR). The hazards and accident analyses show that risks are low, even with operations involving hazardous material. PF-4 is the only facility of its kind still operating in the US.

\subsubsection{Existing Facility Status}

Since TA-55 began operations in 1978 , it has been operating in a safe manner performing its principle missions: basic SNM research and technology development; processing a variety of plutonium-containing materials; and preparing reactor fuels, heat sources, and other SNM devices. In addition, a wide variety of nuclear material is stored at TA-55. To meet the new challenges in 


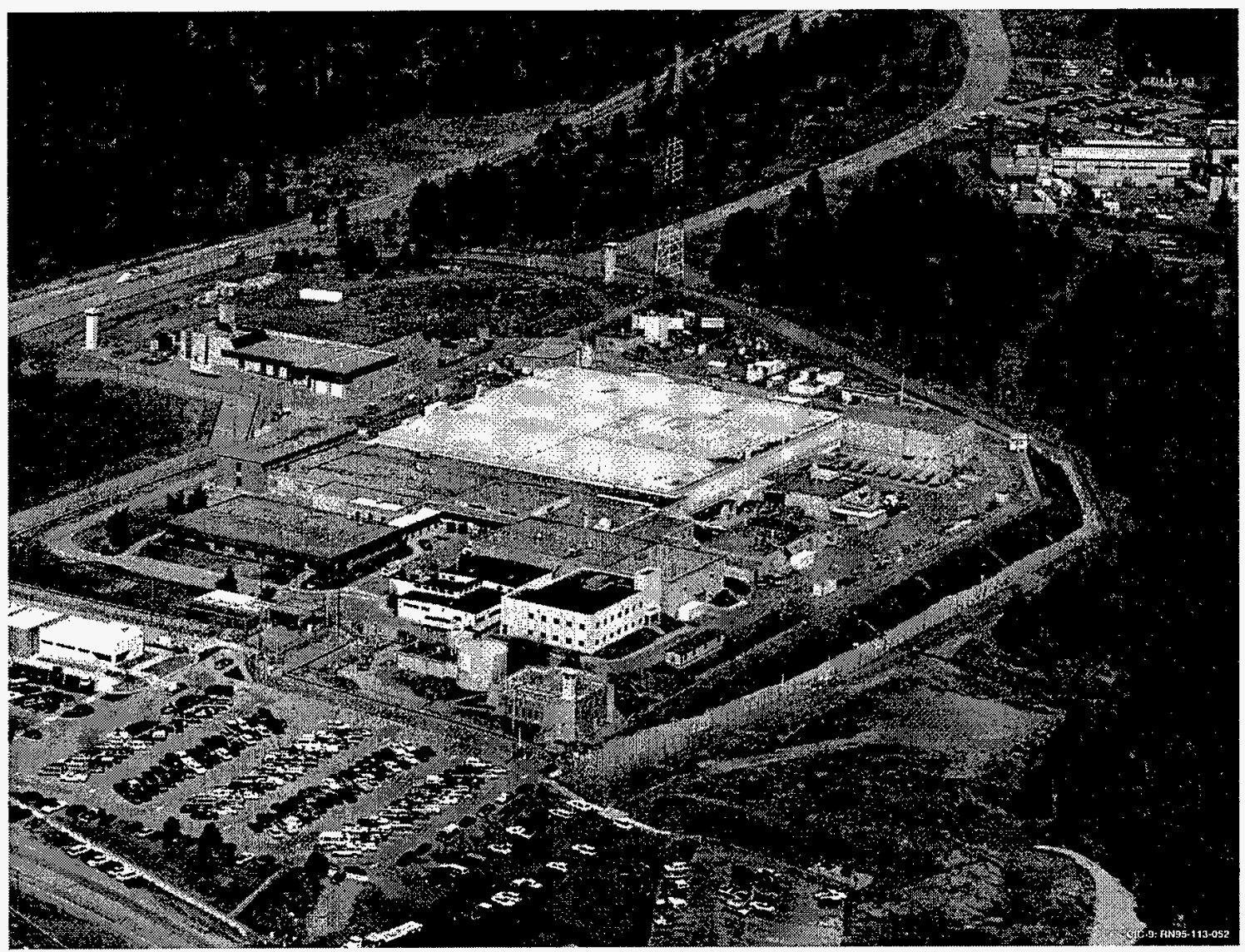

Fig. 3. Aerial view of TA-55.

the world today, TA-55 has begun activities relating to nuclear stockpile stewardship; residue, waste, and environmental cleanup; advanced nuclear energy concepts; and nuclear material management and safeguards.

At the time of initial operations, an FSAR and operational safety requirements [presently called technical safety requirements (TSRs)] were approved by the DOE for TA-55. Efforts have been ongoing for several years to meet newer requirements and to upgrade the FSAR and TSRs. The upgraded FSAR and TSRs will provide the necessary information to meet the requirements of DOE Order 5480.22, Technical Safety Requirements and DOE Order 5480.23, Nuclear Safety Analysis Reports. DOE-STD-3009-94, Preparation Guide for U.S. DOE Nonreactor Nuclear Facility Safety Analysis Reports, was used in the preparation of the FSAR and TSRs.

The quantities of hazardous material that are located within and adjacent to PF-4 were compared with the threshold quantities that are listed in DOE-STD-1027-92. The quantities within PF-4 exceed the threshold quantities of ${ }^{238} \mathrm{Pu}$ and ${ }^{239} \mathrm{Pu}$ for a Hazard Category 2 facility. PF-4 is designated as a Hazard Category 2 nuclear facility because it does not have a potential for significant off-site consequences. 


\subsubsection{Previous Use}

The principle operations conducted in PF-4 involve plutonium processing. Also, a variety of other operations are conducted, including nuclear material research and development, reactor fuel element development and assembly, radioisotope heat source development, nuclear waste process research, and SNM operations. The principle nuclear materials used are ${ }^{238} \mathrm{Pu},{ }^{239} \mathrm{Pu}$, and ${ }^{235} \mathrm{U}$, but a variety of other isotopes are also used in operations. Metals, carbides, oxides, nitrides, and other compounds are used in solid and aqueous solutions. The solids are in powders, buttons, billets, pellets, sintered compacts, and other forms of various sizes and shapes. The type, shape, size, form, and usage of nuclear material make safety of operations a vital concern. Facility operations included process-related activities, transportation within the facility, waste-management operations, facility utilities operations, maintenance activities, and storage of hazardous material.

\subsubsection{Advantages for MOX Fabrication Utilization}

TA-55, PF-4 has an established safety record, a sizable experienced staff, and a well-established support infrastructure. The Laboratory organization responsible for operations in $\mathrm{PF}-4$ is the Nuclear Materials Technologies (NMT) Division. NMT Division comprises groups that conduct many different types of operations. Some of the services provided by these groups include safety, training, facility management, and scheduling. The division is headed by a division director and deputy with administration provided by an administrative support office. A DOE facility representative is located on site to provide safety overview.

In addition to the NMT Division, other organizations at the Laboratory provide support to PF-4 operations. This support includes security, radiation protection, criticality safety, safety overview, analytical chemistry, air quality, and waste management. Most of the maintenance, construction, and custodial support is coordinated by the Facility, Security, and Safeguards (FSS) Division and is provided by a support services subcontractor. Environmental, Safety, and Health aspects, such as radiation protection, criticality safety, industrial hygiene and safety, and occupational medicine are provided by groups within the Environment, Safety, and Health (ESH) Division with many responsible individuals stationed within TA-55. Independent safety overview, audits, and operational compliance determinations are conducted by an independent Laboratory Audits and Assessments Office. This office performs a detailed annual safety assessment for TA-55 and tracks compliance with safety recommendations and findings. Periodically, safety overviews are performed at TA-55 by DOE area, field, and headquarters offices.

The Facilities Management Group, NMT-8, ensures that TA-55 is operated within the approved safety envelope. NMT-8 is also responsible for development of the FSAR and TSRs. Other Laboratory divisions (e.g., ESH Division), as well as various subcontractors, assist in FSAR development.

\subsection{RAMROD Facility}

Rod nondestructive examination and bundle assembly will be carried out in the RAMROD facility. RAMROD is located in TA-50, directly across from an internal Laboratory road from TA-55/PF-4. Figure 4 shows an aerial view of RAMROD. Because the facility is adjacent to TA-55/PF-4, time and costs associated with securely shipping the rods to and from RAMROD, and shipping the inspected assemblies back to PF-4 for storage or shipment, are minimized. It is anticipated that a "just In time" bundling approach will be utilized, with the bundles being assembled from stored rods shortly before they are required. The assembled and inspected bundles could then either be stored for a short time at RAMROD, moved back across the road to PF-4 for storage in the basement and eventual shipment, or shipped directly from the RAMROD egress bay. 


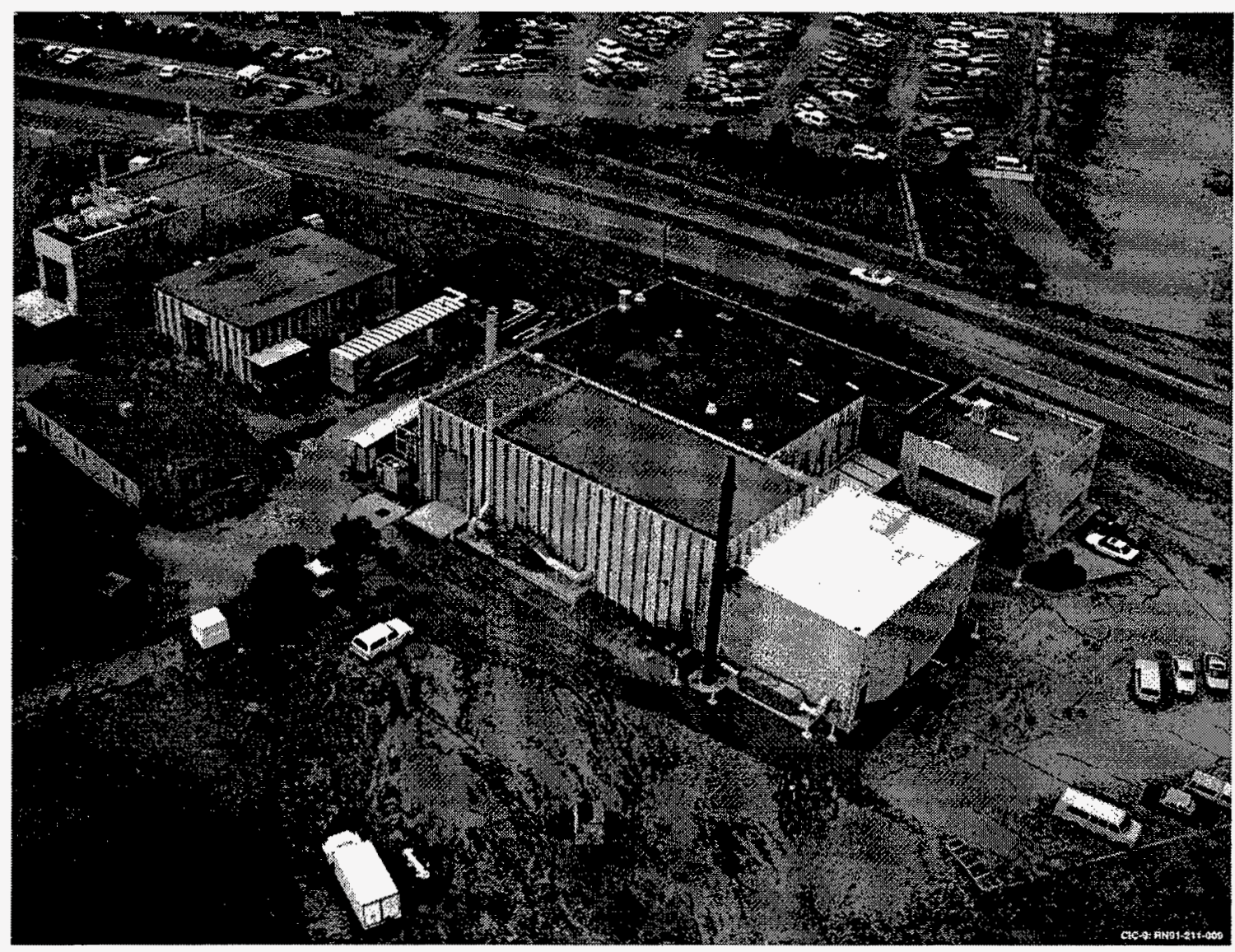

Fig. 4. Aerial view of the RAMROD facility.

RAMROD has a high bay equipped with a five-ton mobile crane with a $25-\mathrm{ft}$ clearance. Ample floor space exists (40 x $80 \mathrm{ft}$ ) and there is direct but securable access to a loading dock (Fig. 5). An additional room in the facility that could be used has a similar high ceiling and $30 \mathrm{x} 40 \mathrm{ft}$ floor space but would require a mobile derrick to be installed for lifting. This would require a simple temporary modification. There are shops available in the building if needed. The building is equipped with a large HEPA filter bank. The facility is uncontaminated. The portion of RAMROD of interest is currently idle, and no other uses are planned for the period of interest.

RAMROD is currently a Hazard Category 2 nuclear facility (per DOE STD-1027-92) and is expected to have final approval from DOE on its SAR and TSR within the later part of FY98. The LA MOX mission is not expected to cause the hazard category to increase. At this time, RAMROD does not comply with the seismic requirements of the DOE natural phenomena protection directive. Consequences of a seismic event with the current structure on the LA MOX bundle would be evaluated as part of the unreviewed safety question (USQ) determination process. RAMROD is not currently an SNM Category 1 facility because no activities involving SNM have previously taken place there. RAMROD would have to be upgraded, on a temporary basis, to an appropriate safeguards Category only during the short time that bundle assembly is occurring [i.e., a temporary Material Access Area (MAA)]. To the extent that bundling and vertical testing will not take much time, this will not be a significant burden. 


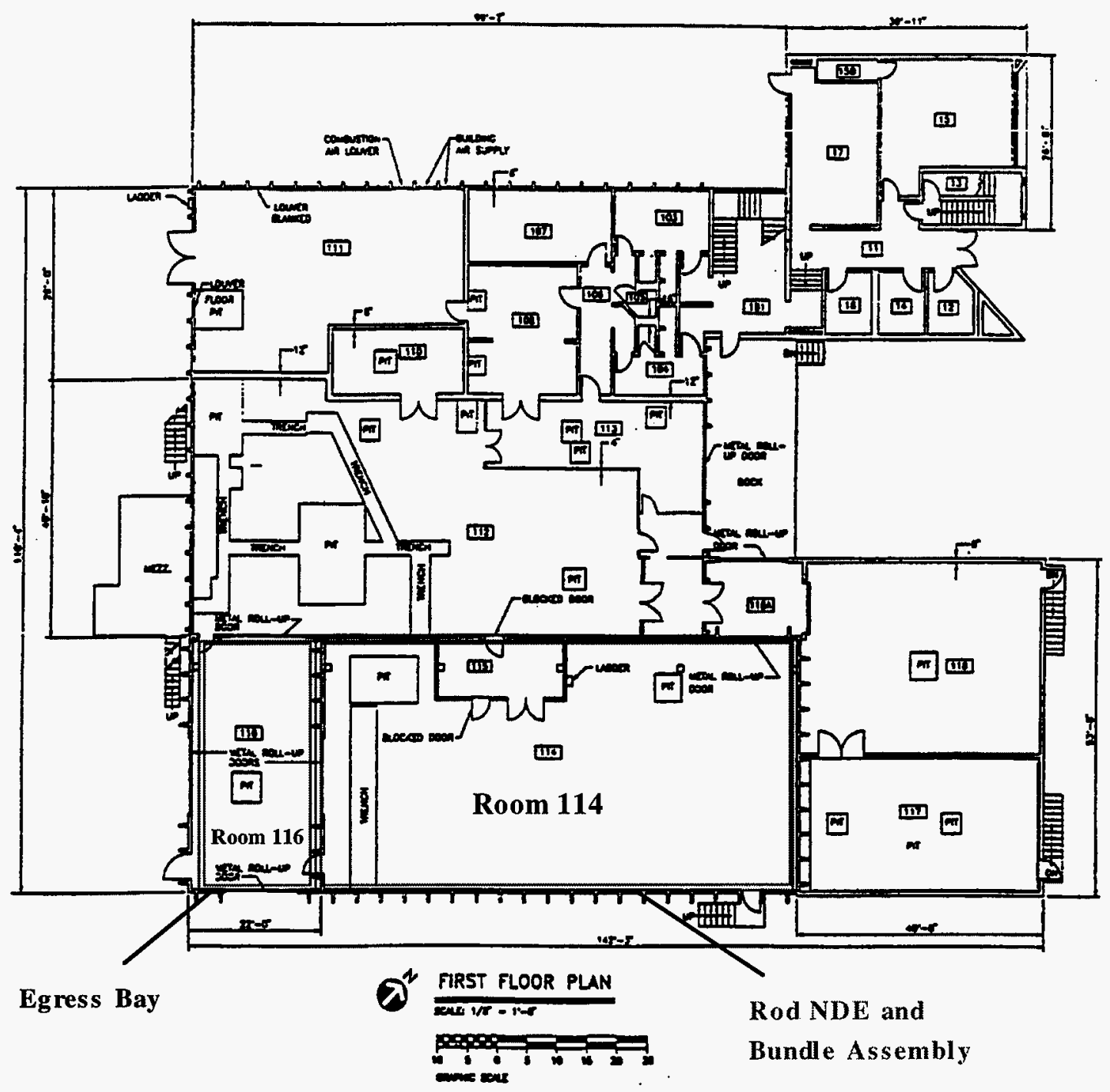

Fig. 5. RAMROD floor plan.

In reference to the storage of MOX fuel rods and air quality [i.e., National Emission Standards for Hazardous Air Pollutants (NESHAP)] requirements at the RAMROD facility, two review processes must occur. First, the facility emissions must be reviewed to determine if stack monitoring must occur. Second, the facility emissions must be reviewed to determine if preconstruction notification to the Environmental Protection Agency (EPA) is required.

Emissions from the storage facility must be estimated to determine if stack monitoring is required. This is done by using methods discussed in the Federal Facilities Compliance Agreement (FFCA) signed by DOE and EPA in October 1996 and by best engineering estimates. This estimate is based on potential emissions without filtration control devices. The MOX fuels are stored in sealed stainless steel or Zircalloy containers. Sealed solid material is estimated to have no potential emissions; therefore, monitoring of the storage facility would not be required under 40 CFR 61 , Subpart $\mathrm{H}$.

For preconstruction review, emissions must be estimated using 40 CFR 61, Appendix D methods. Appendix D states that emission estimates to the atmosphere are performed by determining the amount (in curies) used at the facility for the period under consideration. Furthermore, radioactive 
material stored in sealed packages that remain unopened and have not leaked during the assessment period should not be included in the calculation. Therefore, a preconstruction approval would not be required for rod NDE and bundle assembly activities at RAMROD.

\subsection{Chemistry and Metallurgy Research Facility}

TA-3 is the Laboratory's largest, main technical area, both in terms of the amount of land space and the number of personnel. It houses a variety of projects and contains a number of buildings/facilities, including the Chemistry and Metallurgy Research (CMR) building (Fig. 6). This building was designed within TA-3 as an actinide chemistry and metallurgy research facility. The main corridor contains seven wings that were constructed in 1952 . In 1960 a new wing (Wing 9) was added for activities that must be performed in hot cells. The three-story building now has eight wings connected by a spinal corridor and contains a total of $51,000 \mathrm{~m}^{2}\left(550,000 \mathrm{ft}^{2}\right)$ of space. Each wing is associated with different activities. Containing hot cells and SNM vaults, CMR now is the only Laboratory facility with full capabilities for performing SNM analytical chemistry and materials science. It currently is designated as a Safeguards Category 3 and Hazard Category 2 nuclear facility with some Safeguards Category 1 capabilities.

The CMR Facility hosts a variety of activities, principally: analytical chemistry, uranium processing, destructive and nondestructive analysis, actinide research and processing, fabrication, and metallography. Enough waste treatment and pretreatment are conducted within the facility to sufficiently meet waste acceptance criteria for both on- and off-site receiving facilities. In addition to being the primary location for many projects, these facilities are used to support various activities at other Laboratory locations.

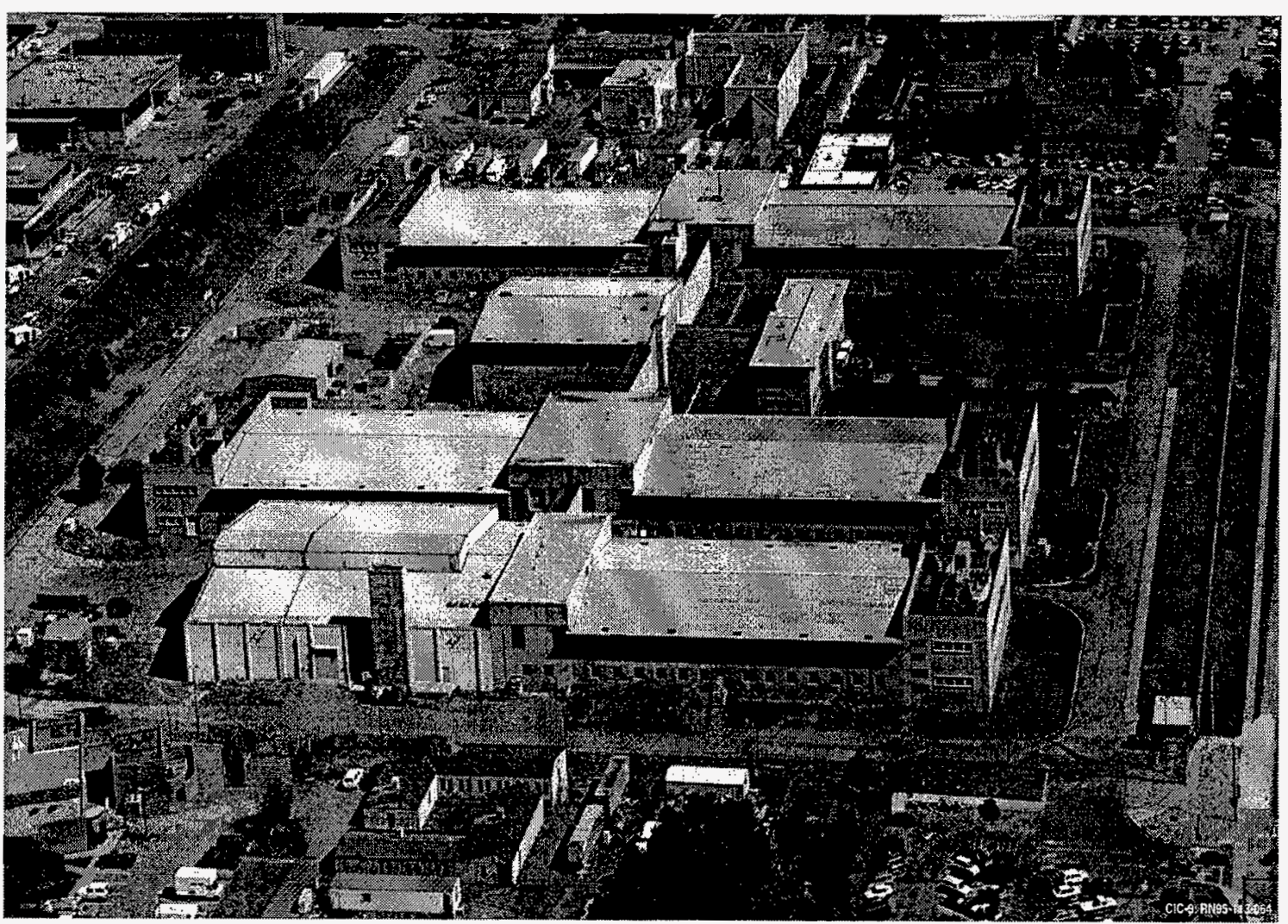

Fig. 6. Aerial view of CMR facility. 
Analytical chemistry capabilities involving the study, evaluation, and analysis of radioactive materials also reside at the CMR Building. These activities support various nuclear materials programs, many of which are performed at other Laboratory locations. Analytical activities include assay and determination of isotopic ratios of plutonium, uranium, and other actinides; major and trace elements in the materials; interstitial gases analysis; highly sensitive surface analysis techniques; and methods to determine environmentally important waste constituents on highly radioactive materials.

The CMR Building is designated as a Hazard Category 2 facility (per DOE STD 1027-92 and DOE-AL-STD-1001-95). The inventory authorized for the CMR Building is sufficiently large to accommodate LA requirements. The scope of activities currently performed within the CMR Building is broad enough that the addition of the LA MOX activities would not increase the hazard category.

The Laboratory temporarily suspended operations at the CMR Building beginning September 2, 1997. This was initiated by Laboratory management to assure that hazards have been systematically identified and sufficiently analyzed, necessary procedures are in place, and requisite training has been completed for all personnel. Certain activities should start resuming operations around November. All activities should resume operation within 2 to 4 months of the suspension date. Thus, the facility will be fully operational before LA MOX activities begin.

The CMR Building is currently operating under a DOE approved justification for continued operation with supporting Interim Safety Analysis Report (ISAR) and Operational Safety Requirements (OSR), which was approved by the DOE/DP as an interim safety basis (ISB) in June 1994. However, a basis for interim operation (BIO) will be prepared in accordance with DOESTD-3011-94 starting in October 1997 and will be submitted for review and approval by DOE/LAAO within 6 months. After DOE approval of the BIO in March 1998, the current draft SAR and TSR will be further revised to resolve Round 2 questions from the DOE headquarters review.

\subsection{SITE INFRASTRUCTURE}

Los Alamos National Laboratory has been operational since the 1940s and has established a large Laboratory-wide infrastructure to serve the needs of a growing scientific community. The response to the questionnaire ${ }^{1}$ provides a great deal of information about the Laboratory site infrastructure, and this section is meant solely to accompany it. For detailed answers to questions, or for additional information, please read the questionnaire response. ${ }^{1}$

\subsection{Utilities}

There are four main utilities that serve the Laboratory: electrical power, natural gas, water, and sanitary waste. They are described in the following paragraphs.

Commercial electric power for the Laboratory site is supplied by the Los Alamos Power Pool, which consists both of the Laboratory and the Los Alamos County. ${ }^{2}$ Public Service Company of New Mexico provides electric power to this pool from two substations. Power from both substations is delivered to the Laboratory at $115 \mathrm{kV}$ to a substation located at TA-5. The $115 \mathrm{kV}$ switchgear at this substation is arranged so that in the event of a failure of either supply line, or any load, the failed portion can be disconnected with a minimum of impact on the remainder of the system. Additionally, a back-up steam electrical power plant is located within the Laboratory to provide up to $\sim 14 \mathrm{MW}$ of power in case of emergencies. TA-55 is provided $13.2 \mathrm{kV}$ electric 


\section{LA-UR-97-5164}

power either from the TA-5 substation or from this back-up plant located at TA-3. The RAMROD Facility and the CMR Building also receive power from one of these sources.

TA-55 also has an emergency/backup power system in case of a power failure. An Uninterruptible Power Supply supports the safety function of both the ventilation system and the Central Alarm System (CAS) by providing smooth, continuous electric power to the local control panels of the ventilation system, the Facility Control System (FCS), the CAS, and the paging system so those systems will remain operable through short-duration power outages. A second backup system includes a diesel engine-driven generator, which provides a source of $480 \mathrm{~V}, 3$-phase, electrical power for selected loads in PF-4 and its support buildings. Lead assembly sintering furnaces and cooling systems will be connected to backup systems as deemed necessary.

Natural gas is purchased from the Defense Fuel Supply Center and is delivered to the Laboratory site through a DOE-owned transmission pipeline. Natural gas is primarily used at the Laboratory for building space heating purposes, although some is used for hot-water heating. The majority of the natural gas purchased by the Laboratory is delivered to central steam plants at three Laboratory locations and is then dispersed throughout the site.

The Laboratory receives its water supply from a large aquifer of ground water directly below the site. Water is plentiful, but it is located fairly deep below the surface. Wells are drilled 2,500 ft deep, with the first 1,000 ft comprised of 12- or 16-in. pipe followed by 1,500 ft of screened pipe. Water flows through material within the earth to reach this screen and seeks a static water level in the steel pipe. It is then pumped by 600 to 800 horsepower pumps to the surface from this level and is chlorinated and stored in tanks for use. The tank storage capacity is $41,000,000$ gal., which is well over the recommended capacity of 30,000,000. A conservation agreement between the Laboratory and Los Alamos County, called the curtailment plan, assures that both are provided with adequate supplies of water.

Sanitary waste from the Laboratory is collected and sent either to a water treatment plant or sewage stations. Its eventual disposal is coordinated with Los Alamos County.

\subsection{Security}

The Laboratory's strategy for protecting SNM, critical facilities, classified matter, and government property is based on the application of a graded, multilayer protection concept supported by an effective protective force (PF) response to detect, deter, and counter adversary activities. SNM facilities are covered by a protection strategy of deterrence, detection, containment, denial or interruption, and mitigation. This strategy protects the target type of radiological sabotage and SNM Category I and II Theft. Procedures that are implemented and followed in this facility include: the Laboratory Radiological and Toxicological Assessment, Safeguards and Security Management Report, MC\&A Plan, MC\&A Procedural Handbook, and the Security Emergency Response Plan.

The strategy for the protection of classified information and material is through compliance with applicable DOE Orders and policies as implemented by the Laboratory. The material is stored, when not in use, in approved repositories, vaults, or vault-type rooms located within approved security areas and is subjected to periodic PF patrols. All individuals with hands-on access to Category I quantities of SNM are required to be enrolled in the Laboratory PSAP program. 
Periodic audits are conducted to ensure the matter is afforded effective physical protection and access (need-to-know) controls, in accordance with DOE requirements. The Laboratory uses a graded approach to the protection of property based on the value of the property in each facility. Strategies include: access control, visitor logs, security alarms, and random property inspections by the PF.

\subsubsection{Protective Force and Physical Security}

PF services at the Laboratory are provided by Protective Technology Los Alamos (PTLA), which is under contract to the Laboratory. The mission of PTLA at the Laboratory is to provide a security force of well-trained and qualified personnel for protecting SNM, information, employees, and government property from theft, diversion, sabotage, and malicious destruction. The PTLA PF conducts security operations in accordance with the PF subcontract and other University of California-approved plans and DOE Orders and directives.

The PF at PTLA is mission-capable to handle security-related incidents as guided by the DOE Security Design Basis Threat statement and policy. The security incident resolution capabilities include: incident assessment, command and control, adversary containment and denial operations, hostage rescue, recapture, and the full spectrum of SRT force option actions. The equipment used by the PF includes firearms, radio and telephone communications, vehicles, and other special equipment. More information on the appropriate strategies for TA-55 are identified in the Protective Force Security Emergency Response Plan.

The Laboratory has a large security force that will provide almost all services needed for the lead assembly program. In particular, all powder, pellet, and rod fabrication activities will take place in PF-4, which is an SNM Category I nuclear facility. There are stringent security measures employed at this facility to prevent unauthorized access and theft. No modifications would be needed at PF-4 for lead assembly fabrication activities.

Bundle assembly will be performed at the RAMROD Facility. Added security measures would be required while bundle assembly activities take place. It is anticipated that bundle assembly will only take a few days at a time, so it is proposed that a temporary MAA with round-the-clock security be implemented at the facility while the rods and/or bundles are there.

The CMR has multiple Category III material balance areas (MBAs). The protection afforded these MBAs is sufficient to protect the analytical functions being performed in the CMR that would support the lead assembly project.

Additionally, the Laboratory has a long standing Memorandum of Understanding (MOU) between the Los Alamos County Police Department and the Federal Bureau of Investigation (FBI). These MOUs describe the scope of the assistance to be provided during emergencies at the Laboratory.

\subsubsection{Materials Control and Accountability}

The Laboratory MC\&A program is designed to address all forms and category levels of nuclear material (NM). This is dictated by the fact that current Laboratory operations require the use and storage of a wide range of accountable NM types and quantities. The MC\&A program is based on the graded safeguards concept of providing the greatest relative amount of control to types and quantities of SNM that can be used in a nuclear explosive device. The MC\&A requirements are based on the category (quantity and attractiveness) of the SNM. The NM types, reporting units, 
and categories are determined as defined in DOE Order 5633.3B and the implementation guide. The NM categorization determines safeguards requirements. Periodically additional security measures are required to support temporary activities. The added safeguards requirements appear in an approved security plan written specifically for the temporary situation. Furthermore, additional safeguards requirements may be necessary for selected materials based on radiological sabotage analysis. Authorized quantities of NM allowed in each MBA are documented in the applicable MBA operating procedure.

The Laboratory implements the requirements of DOE Order 5633.3B through both the MC\&A Plan and the MC\&A Procedural Handbook. The MC\&A Plan is approved by DOE and provides a broad overview of the Laboratory MC\&A system. The MC\&A Procedural Handbook is a Laboratory-level document that provides detailed guidance for the various aspects of the MC\&A system. These include materials accounting, internal and external transfers, measurements along with measurement control, administrative controls, such as the Internal Review and Assessment (IRA) program, Process Accountability Flow Diagrams, access controls, materials surveillance, materials containment and detection/assessment, as well as the physical inventory process and MC\&A training/certification.

\subsection{Fire Protection}

There are fire department facilities located within three miles of the main facilities proposed for lead assembly fabrication activities. The fire department facilities are well-staffed and can respond within 3 to $10 \mathrm{~min}$ of an emergency call depending on the location of the facility (it would take less than $5 \mathrm{~min}$ for TA-55 and TA-50, and less than $3 \mathrm{~min}$ for the CMR Building, etc.). In addition to the main fire department that serves the proposed facilities, there are secondary, back-up departments to support additional fire protection needs.

Additionally, there is a group at the Laboratory (FSS-21), which is completely devoted to fire protection services at the Laboratory. This group deploys workers to various facilities (including TA-55) to oversee fire safety concerns. These individuals will oversee all lead assembly activities for fire protection purposes.

\subsection{Analytical Laboratories}

The majority of the analytical work performed at the Laboratory takes place in the CMR Building. The Laboratory is currently fabricating MOX fuel for the FMD Program, and as such, has a complete and operational analytical capability. This includes both ceramic assessment (particle size, surface area, oxygen-to-metal ratio, microstructure, homogeneity, surface finish, density, etc.) and chemistry (bulk and trace element concentration, gallium spatial distribution, U/Pu assay, etc.) capabilities. Some of these processes occur within the glove boxes in PF-4, whereas others are conducted in the CMR Building.

As an alternative, there are several other facilities containing laboratories that can be used for analytical work. The Laboratory will be in the process of setting up dedicated facilities within PF- 
4 in the near future to support directly both the FMD MOX and FMD ARIES programs. The Materials Characterization and Analytical Chemistry Group, CST-15, will have capabilities within PF-4 that are similar to those provided by the CMR Building. The Radiochemistry Facility at TA48 can provide isotopic and impurity analyses for small samples.

\subsection{Waste Handling}

The Laboratory has several waste management facilities used for the handling, processing and/or storage of all waste types, including transuranic (TRU) contaminated equipment and other large contaminated items. The liquid waste management facilities are located at TA-50, whereas the solid waste management facilities are primarily located at TA-54.

One liquid waste management facility at the Laboratory is the Waste Characterization, Reduction, and Repackaging Facility (WCRRF). The WCRRF has the capability to receive large contaminated items, such as glove boxes and major equipment. These items are decontaminated within a HEPA filtered confinement system, reduced in volume, and packaged in containers that are acceptable for storage at the Laboratory's Transuranic Waste Storage and Low-Level Radioactive Waste Disposal Facility at TA-54 (Area G). Liquid TRU wastes from the decontamination process and other processes site wide may be transferred to the Radioactive Liquid Waste Treatment Facility (RLWTF) located in TA-50 where they are treated and solidified. This treated water is then discharged nearby, and the sludge containing the radioactivity is removed from the wastewater and sent to TA-54.

There are two main types of waste streams through which liquid waste is transported from TA-55. These are an industrial waste stream for low-level waste (LLW) and an acidic and caustic waste stream for TRU waste. The only difference between the two is that the acidic and caustic waste stream is pretreated before it is released into the industrial waste stream. Currently, no liquid waste is generated from the rooms in which MOX fuel-fabrication activities take place. This is because no wet processes take place, and it is proposed that only dry processes will take place for lead assembly activities. A number of janitorial sinks exist in PF-4 and would probably be used in any decontamination activities (removal of glove boxes). The liquid wastes that are created through cleaning at these janitorial sinks would become part of one of the waste streams that go to the RLWTF. Any wastewater generated from men's and women's showers in PF-4 is considered uncontaminated and is disposed down the sanitary waste line at TA-55.

The Laboratory's Transuranic Waste Storage and Low-Level Radioactive Waste Disposal Facility is located at Area G in TA-54. Solid TRU wastes (including major contaminated equipment processed by WCRRF) are being temporarily stored here until they can be shipped off site for disposal at the Waste Isolation Pilot Plant (WIPP) or a similar facility. The Laboratory is currently the only site that has been certified to ship waste to WIPP having has passed all of the quality assurance audits [EPA, DOE, and the New Mexico Environment Department (NMED)] necessary for shipment of waste to and acceptance of waste by WIPP.

The amount of TRU waste generated, according to the volumes predicted in the Baseline Assumptions and Guidelines for Evaluating DOE Sites to Fabricate MOX Fuel Lead Assemblies is $65 \mathrm{~m}^{3}$ over three years (or $20 \mathrm{~m}^{3} / \mathrm{yr}$ ). These quantities are relatively large when compared with the total amount of TRU waste generated by the Laboratory every year $\left(20 \mathrm{~m}^{3}\right.$ compared with $73 \mathrm{~m}^{3} / \mathrm{yr}$ ). They are also much larger than the amounts that are being generated in the current MOX fuel-fabrication activities in support of the Materials Disposition program $\left(0.62 \mathrm{~m}^{3}\right.$ annually). Nonetheless, there is still a large amount of storage capacity remaining at the Laboratory for TRU waste, which is expected to be sufficient for the Laboratory for at least the next 20-25 yr. Sixty-five cubic meters of TRU is a small fraction of this lifetime storage capacity. 
Area $\mathrm{G}$ is also the designated disposal area for solid LLW generated at the Laboratory. The LLW is buried in pits underground, and the TRU waste is placed in storage containers on pads, in shafts, or under domes on top of the LLW. The amounts of LLW that would be generated by early fabrication are fairly small compared with total waste generated by the Laboratory as a whole $\left(20 \mathrm{~m}^{3}\right.$ compared with $\left.3828 \mathrm{~m}^{3}\right)$ every year. However, the storage area at the Laboratory is almost full, and a new LLW disposal facility is needed. Such a facility would be required if the early fabrication mission occurred here or not, so it would not be an additional requirement for lead assembly activities.

The Laboratory is a fully functional and operating plutonium processing site. All anticipated waste streams are consistent with permitted activities at the Laboratory. Because MOX fuel fabrication already occurs at the Laboratory, and wastes currently meet regulations, the continuation of fuelfabrication activities should not contribute significantly more waste than that already being generated annually.

\subsection{Support Services}

The Laboratory contains a large variety of support services that would aid lead assembly activities, including:

- 24-h Medical Services/First Aid

- Emergency Response Programs (including a Hazardous Materials Response Group, a current (1995) Emergency Management Plan, a TA-55 Emergency Response Team, and a Site-Wide Alert Notification System)

- Extensive Training Programs

- Facility Maintenance/Custodial Services

- Radiological Control Technicians (RCTs)

- Badge Office

- DOE Area Office

- Research Library

- Computer Services Personnel

- Telecommunications Group

- Quality Management

- Human Resources

- Legal Services

- Classification Group 


\subsection{Regulation and Permitting}

The Laboratory is a DOE-owned facility that is managed and operated under contract by the University of California (Contract Number W-7405-ENG-36). The most current Supplement Agreement to this contract is available for viewing on the World Wide Web at the address: http://www.llnl.gov/comix/comix/. The DOE directives listed in this contract can be obtained from the address: http://www.llnl.gov/comix/comix/bfm/app_g.html. The major permits obtained by the Laboratory deal with environmental compliance issues, and they are presented in Section 8.1.

PF-4 has an FSAR and Technical Safety Requirements (TSR) document that have been reviewed and approved by DOE Headquarters. The DOE Safety Evaluation Report (SER) for TA-55 was issued on January 13, 1997. Currently, PF-4 meets all regulations and the authorization basis for the fabrication of MOX fuel pellets and rods, and it should remain in compliance until well after the lead assembly program is completed. However, changes in glovebox configuration and the addition of new glove boxes and commercial scale equipment will require the preparation of an Unreviewed Safety Question Determination (USQD). These issues would be a routine part of the planning process and have been routinely coordinated with DOE approval authority and will not impede the start of the lead assembly activities. TA-55 also has an NMED (New Mexico Environmental Department) permit for handling beryllium, but this should not be needed for MOX lead assembly activities.

The RAMROD Facility is not currently authorized to handle MOX fuel and/or plutonium in the quantities proposed for this project; however, necessary modifications to existing documentation will be minor. The unresolved safety question determinations and the SARs for the RAMROD facility will have to be updated to handle fuel rods and/or bundles. RAMROD currently has an approved SAR; however, because of facility modifications and upgrades, both the SAR and TSR are being rewritten and should be approved by DOE within the later part of FY98.

The CMR Building is currently operating under a DOE-approved justification for continued operation with supporting ISAR and Operational Safety Requirements OSR, which was approved by the DOE/DP as an ISB in June 1994. However, a BIO will be prepared in accordance with DOE-STD-3011-94 starting in October 1997 and submitted for review and approval by DOE/LAAO within 6 months. After DOE approval of the BIO in March 1998, the current draft SAR and TSR will be further revised to resolve questions from the DOE headquarters review.

\subsection{Safety}

There is an entire organization at the Laboratory that is devoted to Environmental Safety and Health for the Laboratory. This organization consists of groups specializing in: Health Physics, Occupational Medicine, Facility Risk Management, Industrial Hygiene and Safety, Criticality Safety, Occurrence Investigations, Standards and Calibration, Hazardous Materials Response, Radiation Protection, Training, Quality Management, Air Quality, Water Quality, Hazardous and Solid Wastes, and Ecology.

Additionally, there are numerous safety committees at the Laboratory that oversee operations. These committees include:

- Animal Care and Use

- Biosafety

- Compressed and Liquefied Gas Safety

- Electrical Safety 
- Explosives Review

- Firearms Safety

- Human Studies Review

- Laboratory Environmental Review

- Laser Safety

- Nuclear Criticality Safety

- Pressure Vessel and Piping

- Reactor Safety

- Tritium Operations Safety

These groups are well-staffed and would be considered adequate for serving the lead assembly MOX fabrication activities. The lead assembly fabrication mission will be both a continuation of ongoing operations and only one of a number of projects with a similar nature, so it is not envisioned that these oversight committees will have to significantly increase their workload for the mission.

\subsection{PROCESS INTERFACE DESCRIPTIONS}

The generic process flow diagram for the fabrication of MOX pellets and rods is shown in Fig. 7 . The diagram for rod NDE and bundle assembly is shown in Fig. 8. Specific processing approaches and equipment depend on the vendor ultimately chosen for the mission.

\subsection{Feed Material Receiving}

Based on the assumption that the $\mathrm{PuO}_{2}$ will arrive at the Laboratory by safe/secure transport (SST), the material will be received directly into PF-4 by TA-55 Shipping and Receiving. PF-4 has a fully functional, secure SST bay, and routinely accepts such shipments. PF-4 is a Safeguards Category I facility, and as such, has surveillance and safeguards in place to receive, unload, and load an SST. PF-4 also has on-site capability to perform all necessary material accountability measurements. The Laboratory, especially PF-4, routinely handles weapons-grade plutonium, and is fully capable of receiving, handling, unpacking, and measuring shipments expected in this program.

It is also likely that prototypic $\mathrm{PuO}_{2}$ feed material, produced by the ARIES demonstration system currently being installed in PF-4, will be available for the LA MOX mission. In this case, receiving $\mathrm{PuO}_{2}$ feed from off site will not be required; material will be moved directly from the PF4 vault to the fuel-fabrication rooms.

The depleted $\mathrm{UO}_{2}$ shipments could be received in a similar manner, but could also be received at any of several other facilities at the Laboratory that are capable of handling $\mathrm{UO}_{2}$ of various enrichments. For convenience, it will be assumed that uranium shipments will be received directly at TA-55. PF-4 also has the capability of receiving and handling enriched $\mathrm{UO}_{2}$ rods should they be deemed necessary by the program. Any other nonnuclear materials, such as rod and assembly hardware, can be received at the Laboratory's Shipping and Receiving Warehouse, and routine deliveries are made to facilities such as TA-55. 


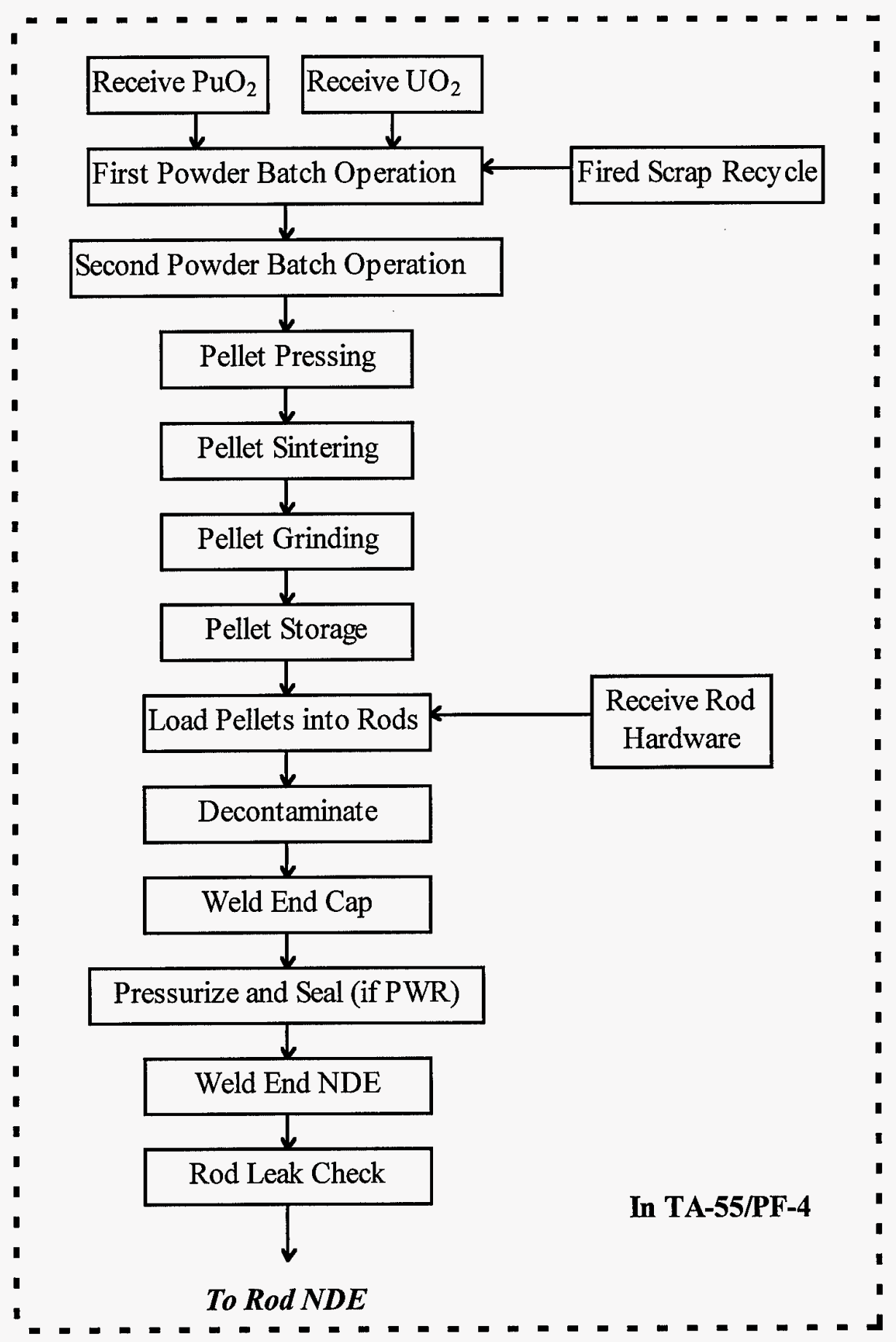

Fig. 7. Generic process flow diagram for rod fabrication. 


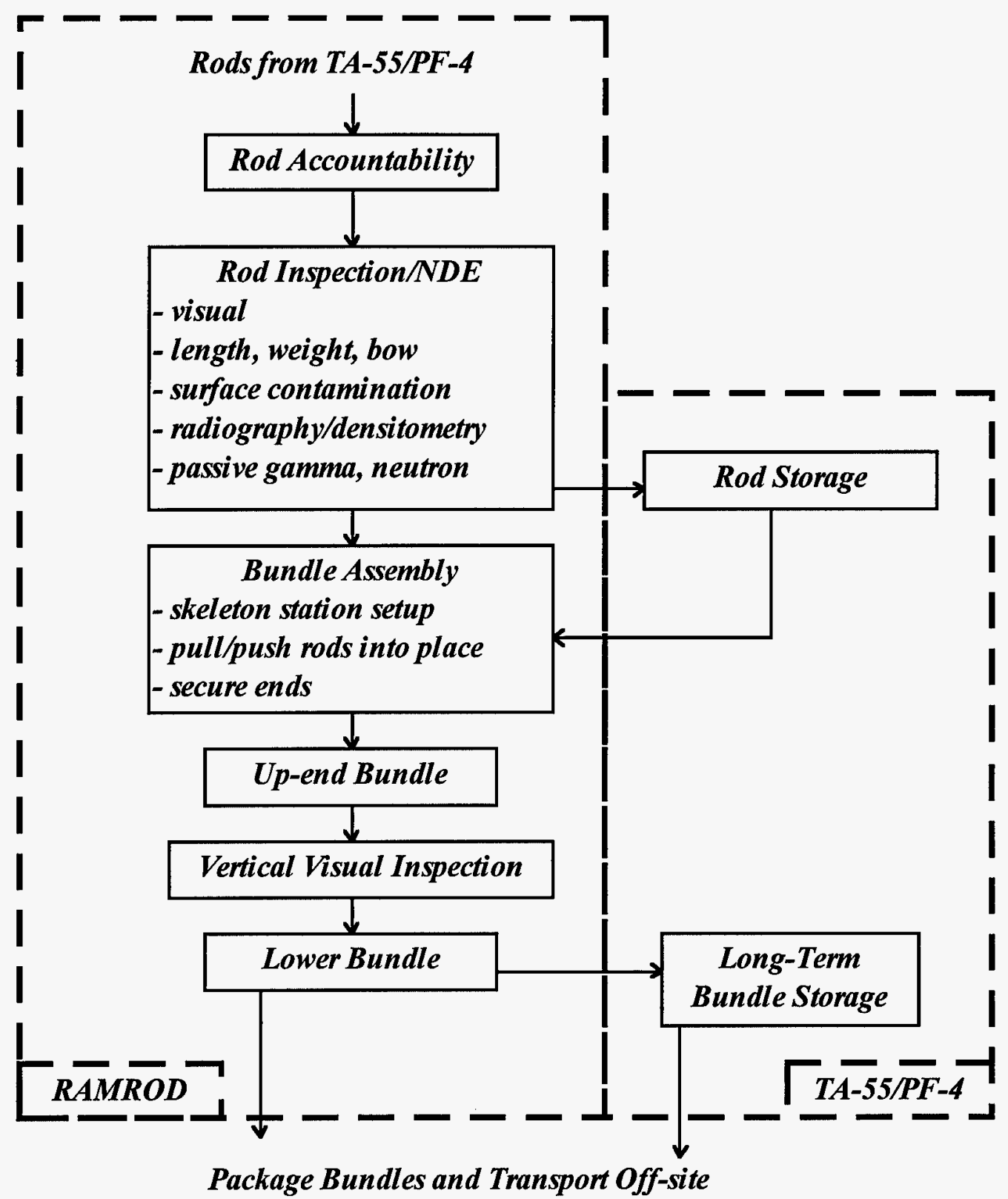

Fig. 8. Generic process flow diagram for rod NDE and bundle assembly.

\subsection{Feed Storage}

Upon receipt, the $\mathrm{PuO}_{2}$ powder will be moved directly into the operational vault in PF-4 where it can be stored until needed. The remainder of the feed materials, including depleted $\mathrm{UO}_{2}$ powder, enriched $\mathrm{UO}_{2}$ rods (if required for bundle completion), and associated hardware, will all be storedin a dedicated caged area in the PF-4 basement. Access to this area will be restricted to protect the materials and is not required for Safeguards and Security compliance. 


\subsection{Blending}

All necessary feed materials (including the $\mathrm{PuO}_{2}$ powder) will be introduced into the glovebox line at PF-4 through an introductory hood (X110) in Room 128. Figure 9 shows a schematic of the hoods and glove boxes already in place in Rooms 128, 126, and 125. This layout, with the associated glovebox numbers, will be referred to in this and the next section (Section 5.4). If the $\mathrm{PuO}_{2}$ feed powder were to be produced by the ARIES Demonstration Project (also in PF-4 at the Laboratory), the material could be transferred to the fuel-fabrication laboratories via the trolley system. For this project, however, it will be assumed that any such powder would be temporarily stored in the PF-4 vault, and, as such, all feed material will be brought from the vault into the glovebox line through the introductory hood.

Once in the glovebox line, materials are transferred between boxes and lines via airlocks and the overhead trolley system. The blending process, which depends on the ultimate fabrication technology selected," is proposed to take place in the three gloveboxes GB-149 (in Room 128), GB-133, and GB-188 (both in room 126). It is assumed that the $\mathrm{PuO}_{2}$ powder will be introduced into the line in standard 3013 cans (with $5.0 \mathrm{~kg} \mathrm{PuO}$ ), which is the can size routinely used in PF4 , and is the largest can one employee can handle readily.

For the MIMAS process, one can of $\mathrm{PuO}_{2}$ will be blended with two $\sim 5.0 \mathrm{~kg}$ cans of depleted $\mathrm{UO}_{2}$ in a high-energy mill in one of these three glove boxes. A master blend with a batch size of $\sim 15.0$ $\mathrm{kg} \mathrm{MOX}$ is then created, with $\sim 30 \%$ plutonium. This master blend is then blended with 17 additional cans of depleted $\mathrm{UO}_{2}$ in a low-energy blender to create a $\sim 100-\mathrm{kg}$ batch of secondary blend with $5 \%$ plutonium in MOX. (This batch size allows a margin of safety corresponding to the individual glovebox limits of $10 \mathrm{~kg}$ of $\mathrm{PuO}_{2}$. Smaller batch sizes are also easily handled. In this scenario, lag storage for powder blends can be accommodated in GB-188.)

Alternatively, if the SBR process is employed, the first blending operation could be performed to achieve $5 \%$ plutonium in MOX by directly blending one can of $\mathrm{PuO}_{2}$ with 19 cans of $\mathrm{UO}_{2}$ in a single-step, high-energy attritor mill. Such a scenario would be proposed to occur in GB-188, which is a larger (taller) glovebox. Press-feed preparation (slug and granulation or spheroidizing) would then occur in the neighboring glovebox (GB-133), and lag storage for powders could be accommodated in one of several nearby boxes.

\subsection{Pellet Production and Inspection}

Once the proper enrichments have been achieved in the blending steps, the pellet production process begins. All of the pellet production and inspection activities are proposed to take place in Rooms 126 and 125 of PF-4 in the existing fuel-fabrication glove boxes. Pellet pressing will occur in G-126. Lag storage for prepress materials can be accommodated in GB-136, while postpress pellets can be stored in GB-137. Both boxes neighbor the pellet pressing box, and all are in line with the sintering furnace.

* For the Micronization and Master Blend (MIMAS) process, this consists of a high-energy milling of a master blend followed by a low-energy blending of the final mix with flowable $\mathrm{UO}_{2}$. For the Short Binderless Route (SBR), this consists of a high-energy milling of the final mix followed by powder press preparation (spheroidizing). Each of these processes has different equipment dimensions. 


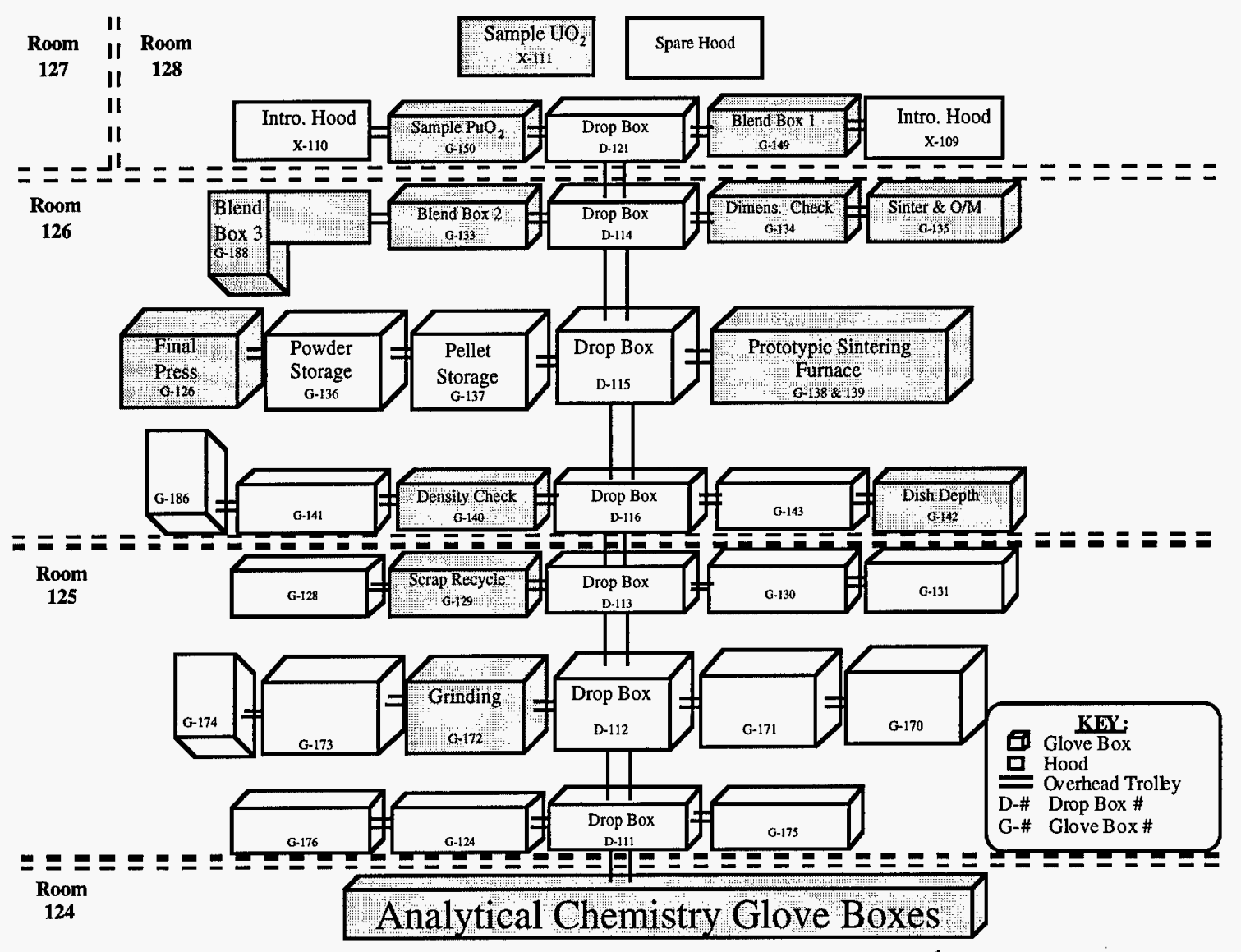

Fig. 9. Process equipment schematic for pellet production.

Green pellets will then pass through the dropbox (DB-115) and enter the sintering furnace through a newly installed introduction glovebox. If a pot-type batch ceramic furnace is used, it will be coupled directly to this introduction glovebox. If a pusher-type continuous ceramic furnace is used, a trolley return system will be incorporated for pellet return after sintering. It is difficult to predict the furnace design because the selected vendor will specify its performance parameters. Several glove boxes are available for storage of sintered pellets in Room 126 . When needed, the sintered pellets will be transferred by overhead trolley to Room 125 , where they will enter the glovebox line at DB-112. Pellet grinding is proposed for GB-172, where there are currently operational centerless grinders. Visual inspection of the pellets after grinding can also occur in GB-172 or in the neighboring box (GB-173). Accommodations have been made for pellet recycle in Room 125 as well. GB-129 currently has a jaw-crusher, and GB-170 and GB-171 are also available for other associated operations. Final pellet storage can occur temporarily in the visual inspection box. For this project, however, it will be assumed that all pellets will be properly stored in the PF-4 vault until needed for rod fabrication activities. In the event it is more convenient or otherwise necessary, finished pellets can be stored in any of a number of idle glove boxes until they are required for rod fabrication.

\subsection{Rod Assembly and Inspection}

The rod assembly process is described to provide an understanding of the capabilities of the existing PF-4 facilities and what commercial/prototypical equipment will be added to PF-4. After receipt at the Laboratory, the packages of empty fuel rods, end caps, and associated hardware will be stored in the secured shipping/receiving storage cage located in the basement of PF-4. When 
needed, packages of fuel-rod components will be brought from the basement to Room 201. They will be secured to a wheeled strongback. The packages will be moved from the shipping/receiving storage cage eastward along the corridor to the elevator, will be placed on the elevator, and brought to the first floor. They will then be moved to Room 201 where they will be placed in temporary storage on horizontal racks located on the west wall or the south wall of the room.

LA MOX fuel pellets will be moved to Room 201 from the basement vault via the elevator to the first floor following the same path used to move the empty fuel rods and components. Alternatively, pellets could be moved from temporary storage in Room 125 or Room 126 to Room 201 via the north corridor. Pellets will be moved on carts in sealed "french-cans" consistent with criticality safety limits. Moving by cart eliminates the potential for contamination of the container during transfer via the overhead trolley system.

The fuel-rod fabrication area is located in the southwest portion of Room 201. The boxes and equipment will start south of D-226. G-295, which is currently a cold (uncontaminated) box used for some welding operations, will be moved to Room 206 as part of a planned consolidation of those operations.

The cans of pellets will be introduced into the line via a new transfer box, which will be isolated from D-226. The inner container will be removed and then transferred through a hatch into the adjacent rod loading box. The hatch will subsequently be sealed. When smears of the outer container confirm that there is no contamination, the outer container will be removed from the transfer box, reused, or subsequently used for waste storage for the pellet fabrication processes.

A tray with pellets of the full range of pellet lengths will be maintained separately from the main loading trays. This will facilitate selection of those pellets necessary to assure overall stack length parameters. (It should be noted here that the specific equipment for loading, welding, and testing of the rods will be designed and selected in conjunction with the requirements of the production consortium to assure demonstration of prototypical processes.)

An empty fuel rod will be placed on the loading fixture, which will maintain the straightness of the rod during pellet load operations. The fixture will be moved to the loading box and locked into place, and the end of the rod will be inserted into the loading box via a sphincter seal. The fixture holding the fuel rod outside of the loading box will be vibrated to facilitate pellet movement through the length of the rod. After the insulator pellets have been loaded, trays of pellets will be moved into position on the pellet loader. As the tray is moved to each successive indexed position, the pellets will be pushed into the fuel rod. The tray will move to the next position and the next row of pellets will be loaded. When a tray has been emptied, the next tray will be moved into position. Each pellet stack will be measured for length via a laser scanner, and the aggregate length loaded into the rod will be maintained. Before inserting the end insulator pellets, pellets of the lengths necessary to meet the overall stack specifications will be selected and inserted. Finally, the end of the rod will be decontaminated and smeared to confirm the effectiveness of decontamination.

After the spring and top end cap are inserted into the fuel rod, the tail stock of the welder will be moved into position to hold the end cap in place. The welding head will be moved into position and the end cap welded in place. The tail stock and welding head will be rotated away from the end cap, and the weld will be visually inspected.

The end of the rod will again be smeared to confirm decontamination. For pressurized water reactor (PWR) fuel rods, the helium pressure fitting with internal tungsten inert gas welding point will be attached to the end of the welded rod. The rod will be pressurized to 20 to $22 \mathrm{~atm}$ [assuming sea level standard temperature and pressure (STP)] of helium. The axial hole will be welded closed, and the pressure fitting will be removed. The rod within the box will again be 
decontaminated, smeared to confirm levels of contamination, then withdrawn from the loading area. The process will be repeated until all the rods on the fixture have been loaded, welded, pressurized, and decontaminated.

While still in the loading box, each rod will undergo weld-end nondestructive examination, including surface contamination check, fixed-alpha contamination check, weld integrity (ultrasonic or $\mathrm{x}$-ray in two $90^{\circ}$ planes), weld dimensions, and perhaps weld end-leak check. The rods will then be moved out of the loading box and to the south side of the room for a sequence of additional activities including mechanical examination, weight, accountability, and full-length rod-leak testing. Sufficient space is available to accommodate these activities.

Once completed, up to 50 loaded fuel rods could be placed on a wheeled strongback with cover and locked within the unit for temporary storage in Room 201 before shipment to RAMROD for NDE. Spacing of the rods on the strongback will be consistent with criticality safety. Loaded fuel rods will be moved inside the strongback carrier to the basement along the same path that the empty rods were brought from storage.

As sufficient finished rods are completed, they will be moved to the RAMROD facility where they will undergo the balance of any required nondestructive examinations. Once at RAMROD, each rod will be verified for accountability purposes and individually inspected. Figure 10 depicts one possible layout of NDE stations within room 114 of RAMROD. Although the eventual suite of examinations performed will be determined by the selected vendor, it is envisioned that the inspection will include a visual, length, weight, and bow determination; surface contamination check; radiographic or densitometry examination; and passive gamma/neutron check for plutonium content and isotopic information. When finished, each rod will have a complete data package and will be shipped across the street to the PF-4 basement cage where they will be stored in strongbacks until bundle assembly is initiated.

\subsection{Rod Storage}

As noted above, loaded fuel rods may be temporarily stored inside the closed strongback carrier within room 201. However, the main storage area for loaded and finished fuel rods (including

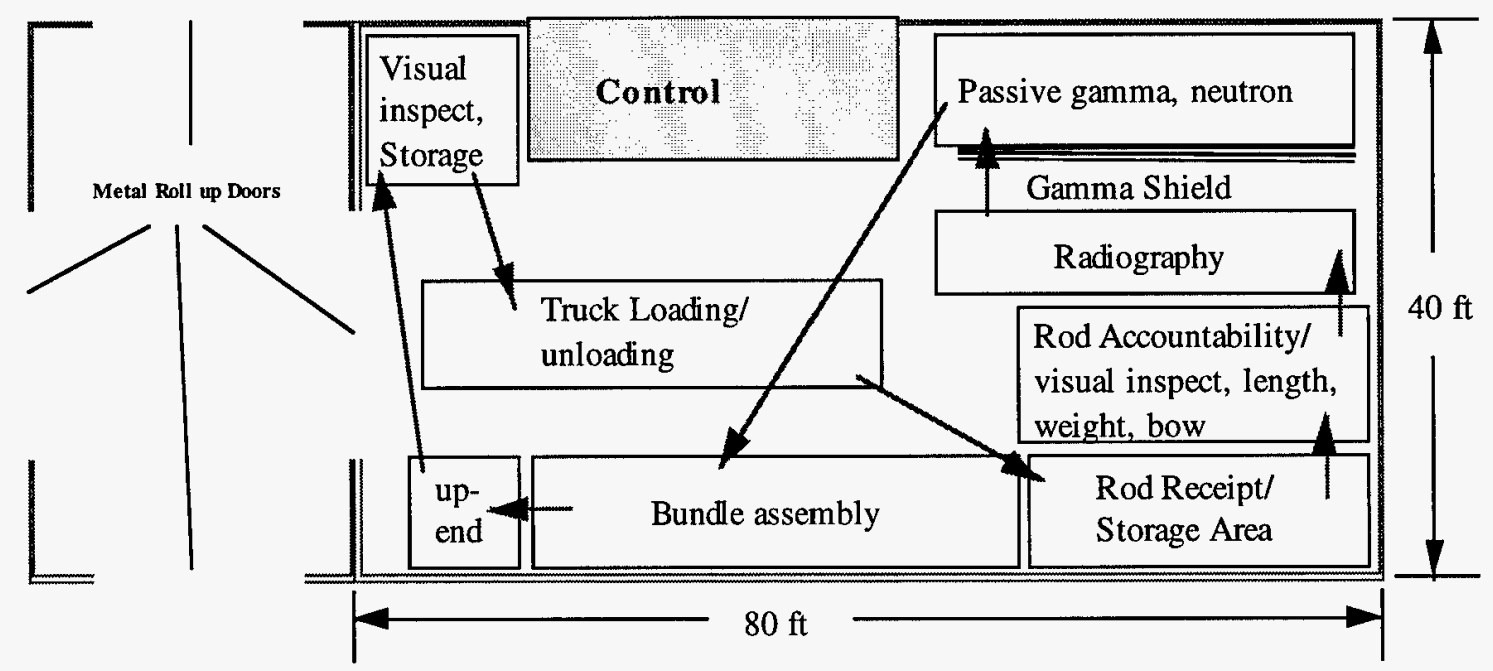

Fig. 10. RAMROD room 114 floor plan with potential NDE and bundle assembly stations. 
NDE) will be in the basement shipping/receiving storage cage. The strongback trays may be detached from the carrier and stacked for maximum storage consistent with criticality safety. The rods will be covered for protection against inadvertent mechanical impact. The loading dock for PF-4 is adjacent to the storage area for ease of transfer.

\subsection{Bundle Assembly}

A central premise of this proposal is the decoupling of rod fabrication and bundle assembly. This allows for the irradiation of fuel rods before complete bundles. Fabrication campaigns for pellets and rods will be oriented according to fuel rod designs. As lots of single-design rods are completed, they will be stored in the finished rod storage area in the basement cage of PF-4. When an adequate inventory of rods is ready for a bundling campaign and the reactor site is ready to receive the lead assemblies, the necessary rods (and their completed data packages) will be transported to RAMROD for bundle assembly. Figure 10 shows a possible layout of the bundle assembly areas within RAMROD.

At this point, two scenarios are possible for the bundle makeup. Because it is unlikely that a full MOX assembly will be required (at least initially), either a partially completed low enriched uranium (LEU) bundle or individual LEU rods will be shipped to RAMROD. In the first case, dummy rods in the LEU bundle will be removed and MOX rods will be pulled or pushed into the assembly. In the second scenario, a skeleton station will be set up where both the LEU and the MOX rods will be pulled or pushed into place and secured. In either case, the completed bundle will be raised to the vertical position by an up-ender. The bundle will be visually inspected, sealed for accountability, lowered, and loaded into cask inserts.

\subsection{Bundle Storage}

The baseline approach presented in this plan assumes that long-term bundle storage will not be required. Bundles will not be built until transportation is authorized and they are needed at the reactor site (i.e., bundles will not be assembled once a minimum number of rods are available). Under this approach, completed bundles in inserts will be loaded into transport casks and will immediately be shipped off site. In the event that long-term storage becomes unavoidable, two possible approaches are possible. The baseline approach is to move the completed assemblies in their inserts back to the basement cage in PF-4. As an alternative, if adequate security can be implemented in RAMROD, vertical long-term storage in room 114 can be implemented.

\subsection{Packaging and Shipping}

As mentioned above, the baseline packaging of completed bundles will take place in the RAMROD facility. The egress bay (room 116) in RAMROD is large enough to accommodate an SST. Bundle inserts with completed bundles can be placed into the transportation cask and loaded into the SST. As an alternative, the cask packaging and SST loading can take place in the shipping/receiving area of PF-4 (in the basement adjacent to the storage cage). 


\subsection{Waste Handling}

The majority of waste that currently is and probably still will be produced from MOX fuelfabrication activities is nonregulated LLW and TRU wastes. The radionuclides that will be present in these wastes consist mainly of ${ }^{239} \mathrm{Pu},{ }^{235} \mathrm{U}$, and ${ }^{241} \mathrm{Am}$. No contaminants, such as lead, are expected, and hence it will not be considered Resource Conservation and Recovery Act (RCRA), or regulated, waste.

Compactible LLW (such as paper, rags, and gloves) are disposed of in cardboard boxes that are $\sim 2 \mathrm{ft}^{3}$ in volume. Ninety of these boxes are packaged together at one time $\left(180 \mathrm{ft}^{3}\right)$ and are placed in a dumpster for shipment to a disposal area such as Area G at TA-54. Other low-level noncompactible waste (such as metal, glass, equipment, etc.) are placed in $90 \mathrm{ft}^{3}$ boxes. When the boxes become full, they are also shipped to a disposal area.

When a relatively small TRU contaminated item or material is removed from a glovebox or a room, it is wrapped in plastic and placed in 55-gal. waste drums for storage. These 55-gal. drums are then stored at Area G (in TA-54) until they can be shipped to the WIPP for disposal. For any oversized TRU waste (such as glove boxes), custom-designed plywood boxes are built for shipment. Additionally, there is a limited amount of space located outside (outdoors) of PF-4 in which oversized TRU contaminated items can be stored until they can be shipped to a Laboratory waste management facility for further treatment and/or storage.

\subsection{PROPOSED FACILITY MODIFICATIONS}

For the lead assembly fabrication effort, all of the activities are proposed to take place within existing, operational facilities at the Laboratory. As MOX fuel fabrication is currently ongoing at the Laboratory, and no major structural modifications are required, it is expected that this portion of the early fabrication effort will be minimal in terms of cost and schedule. Section 6.1 describes needed modifications, which are limited mainly to installation of the few pieces of MOX fuelfabrication equipment needed to upgrade the already functioning fuel-fabrication laboratories at the Laboratory. Section 6.2 describes the small amount of effort required to bring all of the facilities to DOE Order compliance.

\subsection{Installation of MOX Fuel-Fabrication Equipment}

Most of the activities for this mission are proposed to occur within PF-4. The operational fuelfabrication laboratories (Rooms 125 and 126), with the existing glovebox line, will be used with minor modifications to fabricate the lead assembly fuel. These modifications are limited to equipment upgrades to meet selected vendor-specific requirements and include:

- purchasing and installing production model blending and milling equipment in existing glove boxes, and

- purchasing and installing a more prototypic ceramic sintering furnace in place of existing glove boxes. Either a pot-type batch or pusher-type continuous design is envisioned.

With the exception of the sintering furnace installation, each of the modifications first requires the removal of the associated piece of existing equipment (performed through removal of the glovebox window). The sintering furnace installation will require the removal of two existing glove boxes 
(including decontamination and decommissioning). Where appropriate for the new equipment, utility lines will need to be added.

Already planned upgrades to Room 124 (next door to the fuel-fabrication laboratories) could provide on-site analytical chemistry capability for the lead assembly fabrication effort, with no effort required as part of this project. The baseline plan, however, is that the majority of the analytical chemistry activities will take place in already operational laboratories within the CMR Building.

The rod loading and welding activities are also proposed for PF-4, in Room 201. For this effort, minor modifications will be needed. One uncontaminated glove box would be relocated, and two new glove boxes would be installed. The appropriate loading and welding equipment would be installed, along with a certain amount of rod inspection capability (vendor defined) and possibly rod storage racks.

The rod inspection and bundle assembly capabilities would need to be established essentially from scratch. These activities would take place in dedicated areas in RAMROD, and the modifications needed would be the procurement and installation of necessary equipment, including: rod storage racks, rod inspection equipment, bundle assembly device, bundle inspection equipment, and bundle storage racks. Only minor structural modifications are expected, mainly to accommodate electrical power needs for the new equipment. RAMROD already has a functional 5-ton crane in place. Bundle storage is an option in RAMROD, but it will most likely be restricted to a temporary basis while bundles are awaiting transport (either to PF-4 or off site). Security upgrades will be necessary for storage of complete bundles, but should be limited to additional personnel or minor physical modifications, such as crane lock-out capability and/or locked cages.

\subsection{Achieving DOE Order Compliance}

The proposed location of all powder processing and rod fabrication activities is in PF-4. This facility is in compliance with DOE Order 5480.23 and has an allowed SNM quantity of two metric tons (this is an unclassified value). PF-4 is a SNM Category 1 facility and is also considered a Hazard Category 2 nuclear facility (per DOE-STD-1027-92). Although the principal nuclear isotopes used are ${ }^{238} \mathrm{Pu},{ }^{239} \mathrm{Pu}$, and ${ }^{235} \mathrm{U}$, a variety of isotopes have been processed in $\mathrm{PF}-4$, and all isotopes are allowed.

RAMROD is not in compliance with current seismic requirements. The SAR for RAMROD is in the final approval stages and will have to be modified to include SNM handling for the bundling operations. Temporary security upgrades for RAMROD only during SNM handling activities were discussed previously in Sections 3.2 and 3.3.

\subsection{RESOURCES AND MANPOWER}

\subsection{Design}

The modifications necessary to implement the lead assembly fabrication effort have been described in detail in Section 6.1. All of the modifications needed involve the existing glovebox line and related equipment. No modifications to facilities or structures are expected; therefore, no significant design resource requirements are expected. 


\subsection{Construction}

As above, the modifications necessary for implementation of the lead assembly fabrication effort have been described in detail in Section 6.1. All of the modifications needed involve the existing glovebox line and related equipment. No modifications are expected to facilities or structures. Therefore, no significant construction resource requirements are expected. The only resource requirement that would see an increase over routine operations would be manpower needed to perform the modifications. The tasks that require the most manpower are modifications to the actual glovebox line including:

- installation of granulator

- installation of blender and mill

- decontamination and decommissioning of two contaminated glove boxes

- installation of sintering furnace

- removal of four uncontaminated glove boxes

- installation of two new glove boxes

- installation of rod loading and welding equipment in clean glove boxes

Based on data obtained from operational experience in PF-4, the number of person-hours required to complete the tasks outlined above were estimated by type of craft support and are shown in Table 7-2, along with the number of involved workers by craft. It was assumed for this estimate that nonglovebox modifications (i.e., installation of storage racks) would not require unusual or significant resources.

For full-scale operation during the lead assembly fabrication effort, several operators will be needed at each stage of the process. Although the Laboratory is currently fabricating MOX fuel in the PF-4 laboratories, it is at a much smaller scale than that proposed here. A scale-up of personnel, both technicians and supervisory staff, will be needed in most of the processing steps. For feed materials receiving and storage, it is anticipated that NMT-4 (the TA-55 dedicated shipping and receiving group) personnel will be sufficient for this program. The same is assumed to be true for rod storage and rod/bundle transportation.

A few assumptions were used for predicting manpower needs for the operational phase of this project:

- A two-man rule is in effect for work in PF-4, so personnel will be incremented in twos.

- Each process requiring technicians also requires one staff member for supervision.

With a few exceptions, for each major operational process step, it is assumed that two technicians (plus one staff member) can handle all stages of that step. This applies to blending (both stages), slug and granulation (if necessary), grinding, and inspection. If multiple presses are utilized, an additional pair of operators will be needed (for a total of four technicians and one staff member). The sintering furnace will be run continuously and most likely will require two shifts of operation. A large process such as this warrants three operators plus one staff member per shift (for a total of six technicians and two staff members).

For rod fabrication, it was assumed that two technicians are needed for each step of the process: loading, welding, inspection, and transfer to storage. Because this occurs in a small area, in a single glovebox line, it was assumed that a single staff member could supervise four technicians. Overall, eight technicians and two staff members will be needed for this stage of the process. 
TABLE 7-2

MANPOWER REQUIRED FOR GLOVEBOX LINE MODIFICATIONS

\begin{tabular}{|l|c|c|}
\hline \multicolumn{1}{|c|}{ Craft Type } & $\begin{array}{c}\text { Manpower Required } \\
\text { (person-hours) }\end{array}$ & $\begin{array}{c}\text { Number of Involved } \\
\text { Workers }\end{array}$ \\
\hline Pipefitters & 2000 & 5 \\
\hline Electricians & 1000 & 3 \\
\hline Sheet-Metal Workers & 1500 & 5 \\
\hline Radiological Control Technicians & 250 & 2 \\
\hline
\end{tabular}

\subsection{Operation}

Bundle assembly will require additional personnel. It is assumed that four technicians could assembly bundles as needed, then once complete, two of the same technicians could perform bundle inspection. It is also anticipated that two staff members will be needed at this stage for supervisory purposes. However, as bundles will only be fabricated as needed, and not continuously, these personnel will not be needed full time. It is believed that the vendor selected to lead this mission will contribute trained personnel from their LEU or European MOX fuel fabrication facilities as needed for rod NDE, bundle assembly, and bundle inspection.

Other personnel needed, such as for waste handling, radiation protection, MC\&A, and craft support, will be used from the dedicated groups already in place for these functions. No additional personnel are expected to be required from these areas for these activities. Similar arrangements will be made for quality assurance and analytical personnel.

\subsection{ENVIRONMENTAL COMPLIANCE}

\subsection{Permitting}

Many Laboratory activities and operations involve or produce liquids, solids, and gases that contain radioactive and/or nonradioactive hazardous materials. Laboratory policy directs its employees to protect the environment and meet compliance requirements of applicable federal and state environmental protection regulations. This policy fulfills DOE requirements to protect the public, the environment, and worker health and to comply with applicable environmental laws, regulations, and orders. Consequently, the Laboratory operates under all applicable federal and state environmental, safety, and health laws, codes, orders, and standards.

Federal and state environmental laws address handling, transport, release, and disposal of contaminants, pollutants, and wastes, as well as protection of ecological, archaeological, historic, atmospheric, and aquatic resources. Regulations provide specific requirements and standards to ensure maintenance of environmental qualities. Laboratory operations are subject to the following major environmental legislation ${ }^{3,4}$ :

- Resource Conservation and Recovery Act (RCRA-includes Solid Waste Disposal, Resource Conservation and Recovery Act Closure Activities, Underground Storage Tanks, Resource Conservation and Recovery Act Compliance Inspection, Resource Conservation and Recovery Act Training, Waste Minimization, Hazardous and Solid Waste Amendments (HSWA) Compliance Activities, and other Resource Conservation and Recovery Act Activities) 
- Comprehensive Environmental Response, Compensation, and Liability Act (CERCLA)

- Emergency Planning and Community Right-to-Know Act (EPCRA)

- Toxic Substances Control Act (TSCA)

- Federal Insecticide, Fungicide, and Rodenticide Act (FIFRA)

- Federal Clean Air Act (CAA)

- New Mexico Administrative Code (particularly 20 NMAC 2.72, "New Mexico Air Quality Toxic Emission Limits")

- Clean Water Act (CWA-includes National Pollutant Discharge Elimination System, National Pollutant Discharge Elimination System Permit and Outfall Reduction, Waste Stream Characterization Program and Corrections Project, National Pollutant Discharge Elimination System Storm Water Program, National Pollutant Discharge Elimination System Compliance Inspection, Spill Prevention Control and Countermeasures Program, and Sanitary Sewage Sludge Management Program)

- Safe Drinking Water Act (SDWA)

- Groundwater Acts [includes development of a Groundwater Protection Management Program Plan (GWPMPP), and New Mexico Water Quality Control Commission Regulations]

- National Environmental Policy Act (NEPA)

- Cultural Resources Acts (National Historic Protection Act, Native American Graves Protection and Repatriation Act, and American Indian Religious Freedom Act)

- Biological Resources Acts (Endangered Species Act, New Mexico Wildlife Conservation Act, New Mexico Endangered Plant Species Act, Migratory Bird Treaty Act, and the Bald Eagle Protection Act)

- Floodplain and Wetland Protection (Executive Orders Pertaining to Floodplain Management and the Preservation of Wetlands)

The EPA, the DOE, the New Mexico Environment Department (NMED), and the New Mexico Environmental Improvement Board (NMEIB) are the principal authorities/regulatory agencies administering the regulations to implement these laws. The environmental permits and approval agreements issued by these organizations include:

- Mixed Waste Federal Facility Compliance Agreement

- New Mexico Environment Department Compliance Orders for Hazardous Waste Operations

- National Pollutant Discharge Elimination System (NPDES) Federal Facility Compliance Agreement and Administrative Order

- National Emission Standards for Hazardous Air Pollutants Federal Facility Compliance Agreement 
- New Mexico Liquid Waste Disposition Regulations

- National Emission Standards for Hazardous Air Pollutants (NESHAP, or 40 CRF 61, Subpart H)

- Air Toxics Permit (not currently needed, but would be required if metal toxicity limits were exceeded)

- Title 5 Permit from the Clear Air Act (from the EPA for significant changes in air emissions)

- RCRA Hazardous Waste Facility

- HSWA

- TSCA PCBs (Polychlorinated biphenyls)

- Groundwater Discharge Plans

- Open Burning

\subsection{Effluent Monitoring}

The Environmental Oversight and Monitoring Agreement (known as the AIP) between DOE and the State of New Mexico provides technical and financial support by DOE for state activities in environmental oversight, environmental surveys and sampling, site visits, and document review. The AIP was originally signed in October 1990 and covers The Laboratory and Sandia National Laboratories, the Waste Isolation Pilot Plant, and the Inhalation Toxicology Research Institute. NMED is the lead state agency under the AIP. The AIP was renewed on October 1, 1995, for an additional five-year period. There are four primary objectives of this program:

1. assess DOE's compliance with existing laws, including regulations, rules, and standards;

2. participate in DOE's prioritization of cleanup and compliance activities;

3. develop and implement a vigorous program of independent monitoring and oversight;

4. communicate with the public to increase public knowledge of environmental matters about the facilities, including coordination with local and tribal governments.

There are three main areas for which effluent monitoring occurs at the Laboratory: air and water quality, soil and foodstuffs, and biological resources. The following sections describe environmental compliance issues in these three areas for 1996 (Ref. 4).

\subsubsection{Air Sampling/Monitoring Programs}

The radiological air sampling network at the Laboratory is designed to measure environmental levels of airborne radionuclides that may be released from Laboratory operations. Laboratory emissions include $\mu \mathrm{Ci}$ quantities of plutonium and americium, $\mathrm{mCi}$ quantities of uranium, and $\mathrm{Ci}$ quantities of tritium and activation products. Particulate matter in the atmosphere is primarily caused by the resuspension of soil, which is dependent on current meteorological conditions. Windy, dry days can increase the soil resuspension, whereas precipitation (rain or snow) can wash 
particulate matter out of the air. Consequently, there are often large daily and seasonal fluctuations in airborne radioactivity concentrations caused by changing meteorological conditions.

The concentration levels of radionuclides allowed in the air are controlled by the Department of Energy's derived air concentration guides and Environmental Protection Agency regulations as well as 40 Code of Federal Regulations (CFR) 61, Subpart H, "National Emission Standards for Emissions of Radionuclides Other than Radon from Department of Energy Facilities." In 1996, the Laboratory's off-site concentration levels of tritium, uranium, plutonium, and americium were well below any applicable standards; on-site concentration levels did not exceed the Department of Energy's derived air concentration guides. Environmental Protection Agency regulations are not applicable to on-site air monitoring stations but were also not exceeded in 1996.

No new air emission sources or major increases in existing air emissions from lead assembly fabrication activities are expected. The MOX fuel-fabrication activities in PF-4 in 1996 contributed a negligible amount to the americium, plutonium, and uranium emissions at the Laboratory, which were in themselves well below applicable standards. The extensive ventilation/HEPA filtered system in PF-4 (see Section CC of the questionnaire ${ }^{1}$ for more information) prevents most particulate discharge. An increase in fabrication activities will not adversely affect air emissions. Nonetheless, an analysis could be performed after operations begin, and appropriate actions would be taken if limits were not met. Requirements for monitoring at the RAMROD Building are discussed in Section 3.2 and 3.3.

Levels of external penetrating radiation (the radiation originating from a source outside the body, including x-rays, gamma rays, and charged particle contributions from cosmic, terrestrial, and man-made sources) are measured with thermoluminescent dosimeters and dose rate monitors. In 1996, MOX fuel-fabrication activities at PF-4 did not contribute to above-background doses of external radiation and are not expected to during the lead assembly fabrication.

\subsubsection{Water Sampling/Monitoring Programs}

Within the Laboratory boundary, sources of surface water include spring snowmelt, summer storm runoff, and flow from outfalls that are permitted by the National Pollutant Discharge Elimination System of the Clean Water Act. Surface water is monitored on and adjacent to the Laboratory and at regional locations. Levels of plutonium, tritium, strontium, americium, uranium, cesium, alpha and beta particles, and gamma rays are measured at these stations. Concentrations of radionuclides in surface water samples may be compared with either the DOE Derived Concentration Guides (DCGs) or the New Mexico Water Quality Control Commission (NMWQCC) stream standards, which reference the New Mexico Health and Environment Department Environmental Improvement Division's Radiation Protection Regulations (part 4, Appendix A). The concentrations of nonradioactive constituents may be compared with the NMWQCC General, Livestock Watering, and Wildlife Habitat stream standards. The NMWQCC groundwater standards can also be applied in cases where groundwater discharge may affect stream water quality.

Wastewater discharges from Laboratory operations go into the existing sanitary sewer and the liquid waste treatment facility (see Section 4.5 for more information), which discharges treated water. In 1996, all water discharge measurements were below the Department of Energy's derived concentration guides that limit potential exposure to the public for radioactive effluents in water. There has been a general downward trend in radioactive levels at most monitoring stations over the past three-and-a-half decades. Surface water is monitored for its content of metals and inorganic chemicals to detect possible contamination resulting from Laboratory operations. Surface waters at the Laboratory are not a source of drinking or household water. 
Groundwater is also monitored to determine its quality. The main aquifer beneath the Laboratory is the primary source of drinking water for the Laboratory and the residents of Los Alamos County. Operations at the Laboratory and discharges from county sewage treatment plants have resulted in detectable changes in water chemistry in some parts of the main aquifer. Several Laboratory test wells showed low levels of tritium resulting from Laboratory operations, but the levels were far below Environmental Protection Agency limits. Based on Environmental Protection Agency standards, these small changes have not degraded drinking water and are not a human health concern. There has been no significant depletion of the amount of water in the aquifer. Additionally, the New Mexico Environment Department (NMED) has been authorized by the EPA to administer and enforce the SDWA within the state.

No water discharges are expected for the lead assembly fabrication activities, so they will not affect any environmental compliances. This is because no liquid radioactive waste is generated from operations because a dry fabrication process is used. The only liquid waste generated will be from cleaning up spills, personnel showers, or other routine maintenance activities. The contribution of the lead assembly project to these activities will be negligible.

\subsubsection{Sediments, Soil, and Foodstuffs}

Sediments are monitored on and near the Laboratory and at regional locations for the presence of tritium, uranium, plutonium, cesium, and strontium. In 1996, data from sediment sampling were consistent with results from previous years; none of the sediment samples showed any activity of radioactive substance that exceeded screening action levels (the level at which cleanup activity is required by the Environmental Restoration Project) except on Laboratory property in Mortandad Canyon, where three stations exceeded the screening action levels for ${ }^{137} \mathrm{Cs}$. Sediments are also monitored for trace metals, such as antimony and mercury, and organic contaminants, such as polychlorinated biphenyls (PCBs). The 1996 results showed no concentrations above the limits of quantitation levels for trace metals and organic contaminants.

Soils are monitored both on and off site for tritium, strontium, cesium, uranium, plutonium, americium, alpha and beta particles, and gamma rays. Historically, all levels were within acceptable values, and no action was required to reduce levels of any radioactive element in the soil. Soils are analyzed for trace and heavy metals, such as iron, lead, mercury, and aluminum. In 1996, all samples were within acceptable levels for the Los Alamos region. Trend analyses show that most radionuclides in soils, particularly tritium and uranium, from both on- and off-site areas, are decreasing over time. The soil sampling and analysis program at the Laboratory is mandated by DOE Orders 5400.1 and 5400.5 .

During 1996, samples of fruits, vegetables, herbal tea, honey, milk, eggs, fish, deer, elk, and domestic livestock were collected from the Laboratory and surrounding areas, including several Native American Pueblo communities, to determine the impact of Laboratory operations on the human food chain. Most foodstuff samples from Laboratory and perimeter locations showed no radioactivity distinguishable from that attributable to natural sources and/or worldwide fallout. Similarly, most heavy-metal elements in produce from Laboratory and perimeter areas in 1996 were within regional background concentrations.

Lead assembly activities should not adversely affect any sediments, soil, or foodstuffs radiation levels. 


\subsection{Waste Generation}

The Laboratory adheres to all state and federal environmental compliances for waste generation, including:

- New Mexico Solid Waste Management Regulations,

- $\quad$ Mixed Waste Federal Facility Compliance Agreement, and

- New Mexico Environment Department Compliance Orders for Hazardous Waste Operations.

In addition, the Laboratory also follows all waste generation legislation, including RCRA and CERCLA, which will be discussed below. All waste generated by the lead assembly project will follow the Laboratory's typical waste compliance activities.

\subsubsection{Resource Conservation and Recovery Act}

RCRA requires the Laboratory to regulate hazardous and solid waste, from its generation to its disposal. RCRA requires the Laboratory to attempt to reduce the amount of hazardous waste produced, the toxicity of generated hazardous waste, and to treat hazardous waste before its disposal. Laboratory staff had frequent interactions with federal and state RCRA personnel during 1996. On October 4, 1995, the State of New Mexico issued the Federal Facility Compliance order (FFCO) to both the Department of Energy and the University of California requiring compliance with the STP and thereby terminating the Federal Facility Compliance Agreement that had previously been in effect.

\subsubsection{Comprehensive Environmental Response, Compensation, and Liability Act}

CERCLA outlines the appropriate responses to certain substance releases to the environment. Based on-site assessments and inspections, the EPA ranks potentially health threatening or environmentally unsound hazards at facilities. Special attention is given to these hazardous sites, which are maintained on a National Priority List. The Laboratory is not included on the National Priority List but is subject to the CERCLA guidelines for remediating Environmental Restoration Project sites that contain certain hazardous substances not covered by RCRA.

\subsection{CONCLUSIONS}

This plan was generated in response to a request by DOE-MD to supply a plan for fabricating MOX lead assemblies at the Laboratory. The use of extensive operating facilities combined with ongoing robust MOX fuel research and development and plutonium processing activities, makes this proposal attractive from a viability perspective. Additional planning is needed to develop cost and schedule estimates.

\subsection{REFERENCES}

1. M. Barr, M. Bowidowicz, J. J. Buksa, R. L. Carlson, S. L. Eaton, R. A. Morley, and H. R. Trellue, "MOX Lead Assembly Fabrication Questions For Characterization of Site Suitability," Los Alamos National Laboratory report LA-CP-97-184 (October 1997). 


\section{LA-UR-97-5164}

2. "Emergency Management Plan," Los Alamos National Laboratory document LA12900/UC-900, compiled by R. J. Honkus and the Emergency Management Response Office Staff (January 1995).

3. "Environmental Surveillance at Los Alamos during 1995," Los Alamos National Laboratory report LA-13210-ENV (1996).

4. "Overview of Environmental Surveillance and Compliance at Los Alamos during 1996," Los Alamos National Laboratory report LALP-97-150 (September 1997). 


\section{M98004326}

||||||||||||||||||||||||||||||||||||||||||||||||||||||||||||

Report Number (14) LA- UR - -97-5164

Publ. Date (11) $1997 / 2$
Sponsor Code (18) $D O E / D P, X F$
UC Category (19) $U C-721$, DOE/ER 